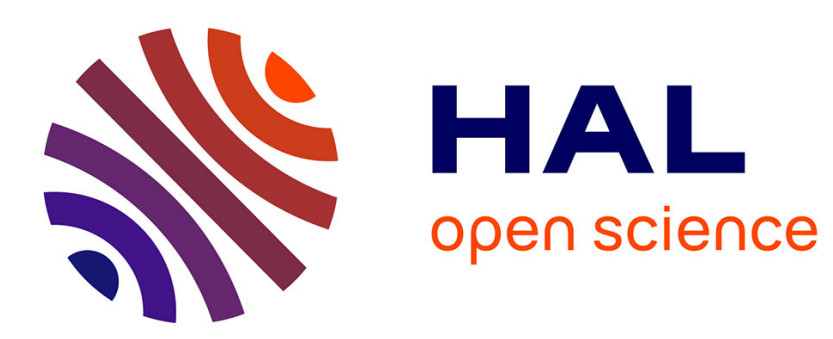

\title{
Évaluation de la chimiothérapie en 2e ligne du cancer bronchique à petites cellules entre 2004 et 2014 en Picardie
}

\author{
Coraline Hybiak
}

\section{To cite this version:}

Coraline Hybiak. Évaluation de la chimiothérapie en 2e ligne du cancer bronchique à petites cellules entre 2004 et 2014 en Picardie. Pneumologie et système respiratoire. 2015. dumas-01288727

\section{HAL Id: dumas-01288727 https://dumas.ccsd.cnrs.fr/dumas-01288727}

Submitted on 15 Mar 2016

HAL is a multi-disciplinary open access archive for the deposit and dissemination of scientific research documents, whether they are published or not. The documents may come from teaching and research institutions in France or abroad, or from public or private research centers.
L'archive ouverte pluridisciplinaire HAL, est destinée au dépôt et à la diffusion de documents scientifiques de niveau recherche, publiés ou non, émanant des établissements d'enseignement et de recherche français ou étrangers, des laboratoires publics ou privés. 


\title{
UNIVERSITE DE PICARDIE JULES VERNE FACULTE DE MEDECINE D'AMIENS
}

Année 2015

$\mathrm{N}^{\circ} 2015-105$

\author{
THESE POUR LE DIPLOME D'ETAT DE DOCTORAT EN \\ MEDECINE \\ Pneumologie
}

\section{Evaluation de la chimiothérapie en 2 ème ligne du cancer bronchique à petites cellules entre 2004 et 2014 en Picardie.}

Présentée et soutenue en séance publique le 17/09/2015

Par

Melle HYBIAK Coraline

Président du Jury:

- Monsieur le Professeur Vincent JOUNIEAUX

Membre du Jury:

- Monsieur le Professeur Henri SEVESTRE

- Monsieur le Professeur Bruno CHAUFFERT

- Madame le Professeur Claire ANDREJAK

Directeur de thèse :

- Monsieur le Docteur Charles DAYEN 
Au président de jury,

\section{Monsieur le Professeur Vincent JOUNIEAUX}

Professeur des Universités-Praticien Hospitalier

(Pneumologie)

Chef du service de Pneumologie et réanimation respiratoire

Pôle «Cœur - Thorax - Vaisseaux »

Vous me faites l'honneur de présider ce jury, acceptez pour cela mes plus sincères remerciements.

Merci pour la qualité de votre enseignement et votre soutien tout au long de mon internat. 
Aux membres du jury,

\section{Monsieur le Professeur Henri SEVESTRE}

Professeur d'Anatomie et de Cytologie Pathologiques à l'UFR de Médecine d'Amiens

Chef du Service d'Anatomie et Cytologie Pathologiques du CHU d'Amiens Picardie

Adjoint au chef de l'Oncopôle

Mes sincères remerciements pour votre participation à ce jury ainsi que mon profond respect.

\section{Monsieur le Professeur Bruno CHAUFFERT}

Professeur des Universités - Praticien Hospitalier

(Oncologie médicale)

Responsable du service d'Oncologie médicale

Oncopôle

Tous mes remerciements pour votre présence dans mon jury et l'intérêt porté à mon sujet. Très respectueusement.

\section{Madame le Professeur Claire ANDREJAK}

Professeur des Universités - Praticien Hospitalier

(Pneumologie)

Merci pour ta disponibilité, ton enseignement au cours de ces 4 années ainsi que ton aide pour mes statistiques.

Je suis très touchée de ta présence dans mon jury. 
A mon directeur de thèse,

\section{Monsieur le Docteur Charles DAYEN}

Praticien Hospitalier

(Pneumologie)

Service de pneumologie de Saint-Quentin

Chef de l'Oncopôle de Saint-Quentin

Tous mes remerciements pour m'avoir proposé ce travail très intéressant, pour ta patience, ta disponibilité et ta gentillesse. Ca a été un honneur de travailler avec toi.

Merci pour ton enseignement dès mon premier semestre. 
A tous mes chefs d'Amiens et Saint-Quentin,

Vous m'avez tant appris pendant ces 4 années, intégré dans cette grande famille et montré la bonne humeur de la pneumologie : Youcef, Rémi, Manue, Marie, Houcine, Claire, Isabelle R., Damien, Eline, Pierre-Alexandre, Julien, Guillaume, Isabelle M., Bénédicte, Estelle, Réda.

\section{A la meilleure Promo et la Coloc de rêve}

Chacha, Flo, Nath et Camille sans qui l'internat n'aurait jamais été aussi drôle, palpitant et pleins d'aventures... Vous avez été tout simplement parfaites.

\section{A mes copines de la fac}

Vous avez toujours été présentes dans les bons et mauvais moments pendant toutes ces années de médecine et je n'en doute pas pour encore de nombreuses années : Anne, Claire, Hélène et Maïlys.

\section{A tous mes co-internes de choc}

Nous avons appris ensemble, nous avons partagé des fous rires et des moments de doute et j'espère sincèrement que nos routes ne se sépareront pas maintenant.

Jean-Baptiste, David, Maxime, Warda, Ottilie, Alexandre, Matthieu, Laure, Aurore, Elodie, Céline, Florent, Fabian.

\section{A mes amis de toujours}

Marion, Julie, Marion (ma sœur twix), Alexis, Lex, Charlotte, Alice, Clément, Quentin R., Fanny, Hubert, Quentin D.

Merci d'être toujours présents pour moi même malgré la distance et je sais que je pourrai toujours compter sur vous.

A tous les Lillois que j'ai pu rencontrer lors de mon dernier semestre. Merci pour votre accueil chaleureux et tout ce que vous m'avez appris.

A toutes les personnes exceptionnelles que j'ai rencontré durant mes études...

\section{A Sina}

Je ne pourrai jamais te remercier assez pour m'avoir soutenue, aidée et surtout supportée en toute circonstance.

\section{A ma famille}

Merci d'avoir toujours été au top pour moi : Maman, Papa, Angélique, Clément et Thomas. Votre aide et votre présence sont inestimables à mes yeux.

A mes grands-parents, oncles, tantes, parrain, marraine, cousins, cousines.

A tous ceux qui nous ont malheureusement quitté trop tôt. 


\section{Résumé}

Introduction : Le cancer bronchique à petites cellules (CBPC) représente environ $20 \%$ des cancers broncho-pulmonaire. Il se caractérise par son agressivité et sa rapidité d'évolution. Au $\mathrm{vu}$ de son pronostic, la question de la réalisation de la $2^{\text {ème }}$ ligne se pose chez beaucoup de praticiens. Le traitement de première ligne est bien codifié mais il n'existe pas de recommandations claires pour la $2^{\text {ème }}$ ligne. Il existe des différences de prise en charge en fonction des centres.

Matériel et méthode : Il s'agissait d'une étude observationnelle, rétrospective, incluant tous les patients ayant bénéficié d'au moins 2 cures de chimiothérapie suivies d'un bilan de réévaluation en $2^{\text {ème }}$ ligne de traitement chez les patients atteints d'un CBPC entre 2004 et 2014 dans les centres hospitaliers d'Amiens et de Saint-Quentin. Les 3 protocoles étudiés étaient : le topotécan seul, le paclitaxel-topotécan et le CEV (cyclophosphamide, épirubicine, vincristine) ou CAV (cyclophosphamide, adriamycine, vincristine). Notre critère de jugement principal était la survie sans progression en $2^{\text {ème }}$ ligne de chimiothérapie.

Résultats : Sur la période de 10 ans, 62 patients ont été inclus dans notre étude. Parmi notre population, $38,7 \%$ des patients ont eu une chimiothérapie par topotécan seul, 35,5\% ont eu une chimiothérapie par paclitaxel-topotécan et $25,8 \%$ ont eu une chimiothérapie par CAV ou CEV. Il n'a pas été retrouvé de différence significative en terme de survie sans progression et de survie globale entre les différents protocoles avec des médianes de survie sans progression respectivement à 3,34 mois $(\mathrm{OR}=0,42$; IC 95\% [2,51-4,17]), 3,57 mois (OR = 0,53; IC 95\% [2,51-4,62]) et 3,11 mois $(\mathrm{OR}=0,49$; IC 95\% [2,15-4,07]). On retrouve une différence significative $(\mathrm{p}=0,032)$ entre les différents protocoles en terme d'effets indésirables (grade > $\mathrm{ou}=2$ de la classification OMS). En ce qui concerne le performance statut (PS) en $1^{\text {ère }}$ et $2^{\text {ème }}$ ligne, il n'a pas été retrouvé d'influence en terme de survie sans progression en $2^{\text {ème }}$ ligne. La présence de métastases cérébrales au diagnostic, la progression cérébrale en $1^{\text {ère }}$ et $2^{\text {ème }}$ ligne n'a pas été retrouvée comme un facteur modifiant la survie sans progression.

Conclusion : Nous avons mis en évidence que la $2^{\text {ème }}$ ligne de chimiothérapie dans le CBPC est bien tolérée chez des patients jeunes et en bon état général. Elle a un réel intérêt en terme de survie. Le CEV est le protocole qui a présenté le moins d'effets indésirables dans notre étude. La radiothérapie stéréotaxique propose probablement les meilleures perspectives pour la $2^{\text {ème }}$ ligne.

Mots clés : Cancer broncho-pulmonaire, cancer bronchique à petites cellules, chimiothérapie, radiothérapie, deuxième ligne, topotécan, paclitaxel-topotécan, $\mathrm{CEV}$. 


\section{Abstract}

Introduction : Small cell lung cancer (SCLC) represents about 20\% of bronchopulmonary cancers. It is characterized by its aggressiveness and rapid-evolution. Basing on the prognosis, the realization of the 2 nd line therapy is controversial by practitioners. The first line treatment is well codified but there is no clear recommendation for the second line. There are differences in management between different medical units.

Material and methods : This was a retrospective observational study, including all patients who received at least 2 courses of chemotherapy followed by a revaluation during the second line therapy in patients with SCLC between 2004 and 2014 in hospitals of Amiens and SaintQuentin. Three protocols were studied : only topotecan, paclitaxel-topotecan and CEV (cyclophosphamide, epirubicine, vincristine) or CAV (cyclophosphamide, adriamycine, vincristine). Our primary endpoint was progression-free survival in second-line chemotherapy.

Results : In the 10 year period, 62 patients were included in our study. Among our population, $38.7 \%$ of patients had chemotherapy with topotecan alone, $35.5 \%$ had chemotherapy with paclitaxel-topotecan $25.8 \%$ had chemotherapy with CAV or CEV. There were no significant differences in terms of progression-free survival and overall survival between the different protocols with median progression-free survival of 3.34 months, respectively ( $\mathrm{OR}=0.42 ; 95 \% \mathrm{CI}[2,51$ to 4.17$]), 3.57$ months $(\mathrm{OR}=0.53 ; 95 \% \mathrm{CI}[2.51$ to 4.62]) and 3.11 months $(\mathrm{OR}=0.49 ; 95 \% \mathrm{CI}[2,15$ to 4.07$])$. There was significantly difference $(p=0,032)$ between the different protocols in terms of adverse events (grade $>$ or $=$ 2 of the OMS classification). Regarding performance status (PS) in 1st and 2nd line, we found no difference in terms of progression-free survival in 2 nd line. The presence of brain metastases at diagnosis, and brain growth in 1st and 2nd line were not modifying the progression-free survival.

Conclusion : We have shown that the second-line chemotherapy in SCLC is well tolerated in younger patients and in good condition. It has a real interest in survival. The CEV is the protocol that presented fewer adverse effects in our study. Stereotactic radiotherapy probably offers the best prospects for the second line.

Keywords: bronchopulmonary cancer, small cell lung cancer, chemotherapy, radiotherapy, second line, topotecan, paclitaxel, topotecan, $\mathrm{CEV}$. 


\section{Sommaire}

$\begin{array}{ll}\text { 1. Introduction } & \text { p.10 }\end{array}$

1.1. Epidémiologie p.10

1.1.1.Données de l'institut national du cancer sur le cancer broncho-pulmonaire p.10

1.1.2. Le cancer broncho-pulmonaire à petites cellules $\quad$ p.11

1.2. Clinique p.12

$\begin{array}{ll}\text { 1.3. Syndrome paranéoplasique } & \text { p.13 }\end{array}$

1.3.1.Syndrome de SCWARTZ-BARTTER : SIADH p.13

1.3.2. Syndrome de CUSHING p.13

$\begin{array}{ll}\text { 1.3.3. Syndrome de LAMBERT-EATON } & \text { p.14 }\end{array}$

1.3.4. Syndrome des auto-anticorps anti-HU p.14

$\begin{array}{ll}\text { 1.4. Diagnostic p.15 } & \text { p. }\end{array}$

1.5. Anatomopathologie p.15

1.6. Biologie tumorale p.16

$\begin{array}{ll}\text { 1.7. Classification, imagerie, bilan d'extension } & \text { p.17 }\end{array}$

$\begin{array}{ll}\text { 1.7.1.Classification } & \text { p.17 }\end{array}$

1.7.2.Imagerie p.17

$\begin{array}{ll}\text { 1.7.3.Bilan d'extension } & \text { p.17 }\end{array}$

1.8. Traitement p.18

1.8.1.Stade IV p.18

1.8.1.1. $1^{\text {ère }}$ ligne $\quad$ p.18

$\begin{array}{ll}\text { 1.8.1.2. } & 2^{\text {ème }} \text { ligne p.20 }\end{array}$

1.8.2.Localisé $\quad$ p.23

1.8.3. Radiothérapie $\quad$ p.24

1.8.4.Irradiation cérébrale prophylactique p.25

$\begin{array}{ll}\text { 1.8.5.Chirurgie } & \text { p.26 }\end{array}$

$\begin{array}{ll}\text { 1.8.6. Soins de support } & \text { p.26 }\end{array}$

\begin{tabular}{ll} 
1.9. Pronostic p.27 & p.26 \\
\hline &
\end{tabular}

$\begin{array}{ll}\text { 2. Matériel et méthode } & \text { p.28 }\end{array}$

$\begin{array}{ll}\text { 2.1. Méthodologie de l'étude } & \text { p.28 }\end{array}$

2.1.1.Type d'étude p.28

2.1.2. Aspect réglementaire et éthique p.28

2.1.3. Objectifs et critère de jugement principal p.28

2.1.4. Sélection de la population $\quad$ p.29

2.1.5.Données recueillies $\quad$ p.29

2.1.6.Protocoles de chimiothérapie p.30

2.1.6.1. $1^{\text {ere }}$ ligne p.30 
3.1. Description de la population et évaluation des pratiques p.32

3.1.1.Description de la population

p. 32

3.1.2. Résultats descriptifs concernant la $1^{\text {ìre }}$ ligne

p.33

3.1.3. Résultats descriptifs concernant la $2^{\text {ème }}$ ligne

p.33

3.2. Critère de jugement principal

p.36

3.3. Critères de jugement secondaires

p. 37

3.3.1. Survie sans progression et survie globale p. 37

3.3.2. Survie globale en fonction du protocole choisi

p.37

3.3.3.Impact du statut initial : disséminé ou localisé ?

p.37

3.3.4. Concernant la $1^{\text {ère }}$ ligne

p.37

3.3.4.1. Présence de métastases cérébrales

p. 37

3.3.4.2. Impact de la réponse en $1^{\text {ère }}$ ligne sur la Survie sans progression

p.38

3.3.5. Concernant la $2^{\text {ème }}$ ligne

p.39

3.3.5.1. Réponse initiale des différents protocoles p.39

$\begin{array}{ll}\text { 3.3.5.2. Impact du PS } & \text { p.40 }\end{array}$

$\begin{array}{ll}\text { 3.3.5.3. Effets indésirables des différents protocoles } & \text { p.42 }\end{array}$

$\begin{array}{ll}\text { 3.3.6.Place de la radiothérapie } & \text { p.42 }\end{array}$

$\begin{array}{ll}\text { 4. Discussion } & \text { p.44 }\end{array}$

\begin{tabular}{l|l} 
4.1.Principaux résultats de l'étude & p.44
\end{tabular}

$\begin{array}{ll}\text { 4.2.Limites de l'étude } & \text { p.44 }\end{array}$

4.3. Tolérance de la chimiothérapie p.45

4.4. Remise en question de la place de la $2^{\text {ème }}$ ligne $\quad$ p.47

$\begin{array}{ll}\text { 4.5.Place de la radiothérapie } & \text { p.48 }\end{array}$

$\begin{array}{ll}\text { 5. Conclusion } & \text { p.50 }\end{array}$

$\begin{array}{ll}\text { 6. Bibliographie } & \text { p.51 }\end{array}$

$\begin{array}{ll}\text { 7. Annexes } & \text { p.55 }\end{array}$

Annexe $1:$ Fiche de recueil de données p.55

Annexe 2: Performance Status selon la classification OMS p.58

Annexe 3 : Classification TNM p.58

Annexe 4 : Effets indésirables selon la classification OMS p.60 


\section{Introduction}

La classification histologique de l'Organisation Mondiale de la Santé reconnait actuellement 4 grands types histologiques de tumeurs bronchiques primitives : les cancers bronchiques non à petites cellules (les carcinomes épidermoïdes, les adénocarcinomes, les carcinomes indifférenciés à grandes cellules) et les cancers bronchiques à petites cellules (CBPC). Le diagnostic repose avant tout sur l'histologie ou la cytologie.

Le CPBC est un cancer agressif, de mauvais pronostic avec une évolution rapide. La réponse initiale au traitement en première ligne a été démontrée car il est radio-chimio sensible. Le pronostic repose sur la réponse à la première ligne. Par contre, il n'existe aucune recommandation bien précise concernant la $2^{\text {ème }}$ ligne.

Dans la pratique courante, les pneumologues et oncologues se posent la question de l'intérêt d'une $2^{\text {ème }}$ ligne. La littérature contient d'ailleurs moins de données concernant celle-ci. Selon les centres, les protocoles diffèrent et cela même au sein des centres. Certains patients bénéficient d'un protocole ou d'un autre mais sans critère reconnu évident. Les 3 protocoles utilisés, ont des historiques différents. Le CEV (cyclophosphamide, épirubicine et vincristine) ou CAV (cyclophosphamide, adriamycine et vincristine) sont des chimiothérapies « historiques » du carcinome à petites cellules. Le topotécan est utilisé dans cette indication depuis une quinzaine d'année de manière courante mais aucune étude n'a prouvé l'efficacité de l'un de ces protocoles par rapport à l'autre. L'association du paclitaxel au topotécan est réalisée dans notre région. Mais là encore, aucune étude n'a démontré son efficacité en $2^{\text {ème }}$ ligne.

C'est dans ce contexte que nous avons voulu voir s'il existait une réelle différence en pratique courante entre ces différents protocoles et faire le point sur la deuxième ligne dans le CBPC. Notre étude s'est intéressée aux patients dans cette indication entre 2004 et 2014 aux centres hospitaliers de Saint-Quentin et d'Amiens.

\subsection{Epidémiologie}

\subsubsection{Données de l'Institut National du Cancer (INCa) sur le CBP}

Le dernier rapport de l'institut national du cancer en 2012 (1), estime à 355000 le nombre de nouveaux cas de cancer par an en France métropolitaine (200 000 hommes et 155000 femmes). Le nombre de décès par cancer est estimé à 148000 par an (85000 hommes et 63 000 femmes). 
Chez l'homme, le cancer broncho-pulmonaire se place au $2^{\text {ème }}$ rang des cancers masculins, avec 28211 nouveaux cas, soit 14,1\% de l'ensemble des cancers masculins (derrière le cancer de la prostate avec 56841 cas). Chez la femme, le cancer du poumon est le troisième cancer incident, avec 11284 nouveaux cas estimés en 2012, soit 7,3\% de l'ensemble des cancers féminins (après le cancer du sein avec 48763 cas et le cancer colorectal avec 18926 cas).

Le cancer du poumon est de loin le plus meurtrier chez l'homme avec 21300 décès estimés (devant le cancer colorectal et prostatique). Chez la femme, le cancer du sein reste le plus meurtrier avec 11900 décès, devant le cancer du poumon et le cancer colorectal.

Le taux d'incidence (standardisé monde) était estimé à 51,7 pour 100000 hommes et à 18,6 pour 100000 femmes. Le taux de mortalité (standardisé monde) était estimé à 27 pour 100 000 hommes et 12,9 pour 100000 femmes. (Figure 1)

Chez la femme, il est en progression constante. Son incidence a été multipliée par 7 ces 30 dernières années (1 526 nouveaux cas en 1980 versus 11284 en 2012). L’âge médian pour le diagnostic est de 66 ans chez l'homme et de 65 ans chez la femme.
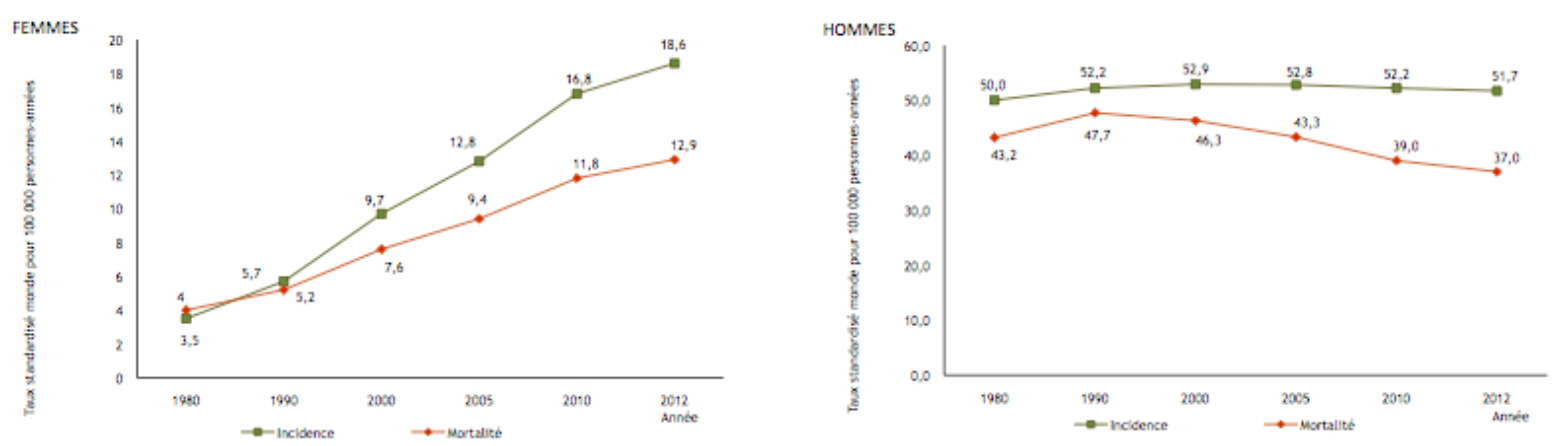

Sources: [Binder-Foucard F, 2013.]. Traitement: INCa 2013

Figure 1 : Evolution de l'incidence et de la mortalité (taux standardisé monde estimé) du cancer du poumon selon le sexe de 1980 à 2012.

\subsubsection{Le Cancer Broncho-pulmonaire à petites cellules}

Même si l'incidence du CBPC tend actuellement à diminuer, il est important de distinguer cette catégorie de cancer broncho-pulmonaire au vu de sa rapidité d'évolution et de son pronostic sombre. 
Les études KBP 2000 et KBP 2010 réalisées en France en 2000 et 2010 dans 104 hôpitaux de France montrent la diminution de l'incidence des CBPC. En effet, en 2010, sur les 7051 nouveaux cas de CBP recensés, 950 étaient des CBPC (13,5\%), alors qu'en 2000, 930 étaient des CBPC $(16,5 \%)(p<0,0001)$. (2) Cette diminution peut s'expliquer par le fait que le CBPC est le type de cancer broncho-pulmonaire le plus lié au tabagisme (Moins de 2\% sont non-fumeurs) et qu'au fil du temps les habitudes de tabagisme ainsi que les profils d'exposition se sont modifiés (mise en place de filtre, modification de la composition, augmentation de l'inhalation et diversification des expositions aux oncogènes). Par exemple, la diminution de la concentration en hydrocarbures aromatiques polycyclique tendrait à déplacer le développement du cancer depuis l'épithélium pseudo-stratifié de l'arbre bronchique principal vers les régions périphériques. La carcinogénèse se porterait plus sur les cellules de Clara et les Pneumocystose de type II. Il y a aussi en cause l'utilisation par les anatomopathologistes de l'immunohistochimie qui reclasserait certains CBPC en carcinomes bronchiques non à petites cellules (CBNPC) (3).

\subsection{Clinique}

La clinique est en général aspécifique et banale ce qui rend le diagnostic plus difficile notamment lors d'une atteinte locale avec des symptômes pouvant se limiter à une toux, une dyspnée, une bronchite trainante, une hémoptysie ou des douleurs thoraciques.

Quand l'atteinte est locorégionale, cela peut se traduire par un syndrome cave supérieur, une dysphonie ou une dysphagie.

Les atteintes à distance sont souvent plus bruyantes avec par exemple en cas de métastases cérébrales la présence d'une symptomatologie neurologique. Dans le cadre des atteintes osseuses, elles peuvent être découvertes par une fracture pathologique ou des douleurs. Dans le cadre des atteintes surrénaliennes ou hépatiques, on peut retrouver des douleurs abdominales.

En règle générale, le tableau au moment de la découverte est « bruyant » avec la présence de signes fonctionnels mais surtout généraux avec possibilité d'anorexie, asthénie et amaigrissement marqués.

L'évolution est souvent rapide car c'est un cancer à croissance cellulaire rapide. Le siège de la tumeur est le plus souvent proximal. Il faut noter que le diagnostic est souvent tardif car 2 tiers des CBPC sont disséminés au moment du diagnostic.

La clinique peut également s'exprimer par la présence d'un syndrome paranéoplasique. 


\subsection{Les syndromes paranéoplasiques}

\subsubsection{Syndrome de SCWARTZ-BARTTER : SIADH}

Ce syndrome est une sécrétion inappropriée d'hormone antidiurétique (ADH). Cela entraine une rétention hydrique se traduisant par une hyponatrémie sévère associée à une hyperhydratation intracellulaire.

Il peut se présenter de manière diverse, sur le plan général par une asthénie. Sur le plan digestif, on peut constater une anorexie, des nausées et des vomissements. Sur le plan neuropsychique, la symptomatologie peut aller de la simple irritabilité, aux céphalées, à la somnolence, la confusion mentale, à la désorientation temporo-spatiale jusqu'au coma.

Les critères cardinaux ont été établis par Bartter et Schwartz en 1967 définissant un SIADH si les cinq conditions suivantes sont réunies :

- hyponatrémie $(<135 \mathrm{mmol} / \mathrm{L})$ et hypo-osmolalité plasmatique $(<280 \mathrm{mOsm} / \mathrm{kg})$

- osmolalité urinaire supérieure à l'osmolalité sanguine

- natriurèse conservée (>20mmol /L) malgré l'hyponatrémie

- absence d'insuffisance rénale, cardiaque, thyroïdienne, surrénale ou hépatique et de prise de diurétiques

- correction de l'hypo-osmolalité par la restriction hydrique.

Le traitement repose principalement sur la restriction hydrique, l'apport en sel, les diurétiques de l'anse avec surveillance des entrées et des sorties. Le traitement par déméclocycline est réservé aux cas d'hyponatrémie inférieure à $125 \mathrm{mEq} / 1$ et en cas de résistance à la restriction hydrique.

Il faut toujours veiller à corriger la natrémie de manière lente afin de ne pas entrainer de myélinolyse centro-pontine.

\subsubsection{Syndrome de CUSHING}

Il se caractérise par une sécrétion ectopique d'ACTH par une tumeur extra-pituitaire. Cela représente environ 10 à $15 \%$ des syndromes de Cushing ACTH-dépendant. Il peut précéder, accompagner ou suivre la découverte du cancer.

La clinique est diverse avec une présence d'une hypertension artérielle, d'une amyotrophie, d'une asthénie, de troubles psychiques, d'œdème des membres inférieurs, d'une hyperpigmentation cutanée (rarement: bosse de bison, obésité tronculaire ou vergetures) 
Biologiquement, on retrouve une hypokaliémie, une alcalose métabolique et une hyperglycémie.

\subsubsection{Syndrome de LAMBERT-EATON}

Le syndrome myasthénique de Lambert-Eaton est une affection neuromusculaire paranéoplasique au cours de laquelle il existe une réponse auto-immune dirigée contre une tumeur pulmonaire à petites cellules et que celle-ci réagit de façon croisée avec des antigènes dans la jonction neuromusculaire. Il représente $2 \%$ des CBPC qui en est la cause la plus fréquente. Dans la majorité des cas, ce syndrome précède le diagnostic de CBPC.

Le tableau clinique peut se traduire par une fatigabilité proximale musculaire, des myalgies ou paresthésies, une amyotrophie, une aréflexie ou une dysautonomie cholinergique (sécheresse cutanée, xérostomie, impuissance).

Le diagnostic se fait par la réalisation d'un électromyogramme. La cause est une réaction auto-immune (présence d'IgG anti-canaux $\mathrm{Ca}^{2+}$ voltage-dépendant) qui entraine une diminution de la libération d'acétylcholine au niveau de la membrane présynaptique.

Le traitement est principalement celui du CBPC. Mais il existe aussi d'autres traitements tels que le chlorhydrate de guanidine qui augmente la libération d'acétylcholine et le 3-4diaminopyridine qui prolonge l'action des $\mathrm{Ca}^{2+}$ voltage-dépendant. Les inhibiteurs calciques et anesthésiques contenant de la succinylcholine (Celocurine $\left.{ }^{\circledR}\right)$ aggravent la maladie.

\subsubsection{Syndrome des auto-anticorps anti-HU}

Ils sont regroupés sous le terme polyencéphalomyélites subaiguës (PEMS). Ils comprennent : l'encéphalite limbique, la rhombencéphalite, la dégénérescence cérébelleuse, la myélopathie subaiguë et la neuropathie sensitive de Denny-Brown.

Moins de $0,5 \%$ des CBPC sont responsables de $80 \%$ de ces syndromes. On retrouve la présence d'anticorps anti-épitropes communs à la tumeur et aux neurones.

Les trois principaux :

- Anti-HU ou ANNA-1 (anti-neuronal nuclear antibody type I)

- Anti-Ri ou ANNA-2

- Anti-Yo ou PCA-1 (Purkinje cell antibody type I)

Il précède souvent les manifestations cliniques et la découverte de la maladie. Le pronostic est mauvais. L'évolution est indépendante avec parfois des rémissions du syndrome grâce au traitement du CBPC. 


\subsection{Diagnostic}

Le diagnostic repose sur une preuve histologique. Pour obtenir cette preuve, il existe plusieurs manières de réaliser le prélèvement :

- Fibroscopie bronchique avec biopsie bronchique: l'aspect évocateur est celui d'une sténose circonférentielle irrégulière plutôt proximale au niveau des axes bronchiques pouvant être liée à une compression extrinsèque avec infiltration de la muqueuse. Mais tous les aspects sont possibles.

- Ponction sous scanner pour les lésions distales de topographie sous pleurale.

- Biopsie pulmonaire par mini-sonde.

- L'écho-endoscopie bronchique avec biopsie transbronchique ou la médiastinoscopie chirurgicale : ces 2 méthodes permettent de réaliser des prélèvements ganglionnaires quand la fibroscopie bronchique ne permet pas le diagnostic.

- Chirurgie thoracique d'une lésion suspecte unique peut être le mode de révélation de la maladie.

- Chirurgie ou biopsie d'une métastase à distance (cérébrale, hépatique, cutanée...) : si seul accès au diagnostic

\subsection{Anatomopathologie}

Les CBPC sont des tumeurs développées à partir des cellules neuroendocrines qui sont dispersées à l'état normal au niveau de la muqueuse bronchique.

Sur le plan macroscopique, il s'agit de tumeurs de développement proximal, péri-hilaires avec fréquemment une extension aux ganglions lobaires, hilaires et médiastinaux. Beaucoup plus rarement elles se présentent sous la forme d'un nodule pulmonaire périphérique ( $5 \%$ des cas). Macroscopiquement, les tumeurs sont blanches, nécrotiques et très friables en raison d'un stroma fibro-vasculaire grêle.

Critères histologiques, histochimiques, immunohistochimiques et ultrastructuraux des CBPC définis par l'OMS (2004)

- Architecture endocrinoïde : nids, travées, massifs palissadiques, formation de rosette ou sous forme de nappes

- Cytoplasme étroit

- Chromatine finement granuleuse 
- Nucléoles non visibles

- Index mitotique élevé

- Coloration de Grimelius positive

- Immunohistochimie : chromogranine +, synaptophysine +, CD56 + et TTF $1+($ dans 90\% des cas)

- Microscopie électronique : grains neuroendocrines intra cytoplasmiques

\subsection{Biologie tumorale}

Dans un tissu sain, il existe un équilibre entre la destruction cellulaire physiologique et la prolifération cellulaire de façon à assurer un renouvellement cellulaire stable. Au cours du processus tumoral, cet équilibre est rompu et la prolifération cellulaire dépasse les besoins du renouvellement. Ce déséquilibre peut être dû soit à une activation d'oncogène (gène codant pour une protéine favorisant la prolifération cellulaire), soit à une inhibition d'anti-oncogène (gène codant pour une protéine régulant négativement la prolifération cellulaire).

Des anomalies chromosomiques ont été mises en évidence et trois zones sont fréquemment atteintes et contiennent la séquence d'un gène impliqué dans le contrôle négatif de la prolifération.

- La délétion du chromosome $3 p$ est retrouvée dans $100 \%$ des CBPC où se situe le gène FHIT codant pour une protéine. Son rôle n'est pas bien connu mais impliqué dans la réplication.

- La délétion du chromosome 13q, porteur du gène de susceptibilité au rétinoblastome $(\mathrm{Rb})$, est retrouvée dans $90 \%$ des CBPC. Le gène $\mathrm{Rb}$ code pour une protéine $\mathrm{Rb}$ régulant négativement le cycle cellulaire.

- Les altérations du chromosome 17q, siège du gène codant pour la protéine p53. Cette protéine joue un rôle majeur dans la régulation du cycle cellulaire (arrêt du cycle), dans la réparation des lésions de 1'ADN ainsi que dans l'apoptose. Elle est présente dans $90 \%$ des CBPC.

Des anomalies moléculaires peuvent également être détectées en immunohistochimie (IHC) :

- Une amplification du gène c-myc avec une hyper expression de la protéine oncogénique cmyc

- Une absence d'expression de la protéine $\mathrm{Rb}$

- Une hyper expression de la protéine p53 (les mutations du gène inactivent la protéine p53 mais la rendent stable, permettant sa visualisation en IHC) 
- L'expression de facteurs de croissance par la cellule tumorale et de leurs récepteurs sur la cellule tumorale, créant ainsi une boucle de croissance autocrine, comme par exemple, le GRP (Gastrin-Related Peptide) et l'IGF I et II (Insulin-like Grouth Factor)

\subsection{Classification, imagerie, bilan d'extension}

\subsubsection{Classification}

Historiquement, on retrouve 2 stades : localisé et disséminé selon la classification VALCSG (Veterans Administration Lung Cancer Study Group) (4). Le stade localisé était défini par les lésions pouvant être incluses dans un champ d'irradiation (hémi-thorax et ganglions lymphatiques régionaux), ce stade correspond au stade I au IIIb de la classification actuelle. L'analyse des données par l'International Association for the Study of Lung Cancer (IASLC) a permis de modifier cette classification et d'étendre la $7^{\text {ème }}$ classification TNM pour les CBPC $(5,6)$ (Annexe 3).

\subsubsection{Imagerie}

La radiographie de thorax (face et profil) est l'examen de débrouillage. Elle permet l'évaluation des atteintes pleurales, parenchymateuses, médiastinales et le dépistage de troubles ventilatoires. Le scanner thoracique permet de préciser la localisation de l'atteinte pulmonaire ainsi que son extension (locorégionale) et d'objectiver la présence d'atteinte hilaire et médiatisnale.

\subsubsection{Bilan d'extension}

Il permet d'évaluer le statut de la maladie par :

- $\quad$ un examen clinique exhaustif

- un bilan biologique complet : ionogramme sanguin, bilan hépatique, lactate déhydrogénase, numération de formule sanguine, bilan de coagulation

- Scanner cérébral ou au mieux une Imagerie par résonnance magnétique cérébrale : à la recherche de localisations cérébrales métastatiques.

- Scanner abdomino-pelvien : afin d'éliminer une atteinte hépatique, surrénalienne, pancréatique, carcinose péritonéale... 
- Scintigraphie osseuse : pour évaluer la présence d'atteinte osseuse si une tomographie par émission de positons (TEP) n'a pas été réalisée.

- Une TEP doit être réalisée lorsqu'un traitement local est envisagé

- Si une radiothérapie pulmonaire ou une chirurgie thoracique est décidée, il est recommandé de prévoir en amont de ses traitements des explorations fonctionnelles respiratoires.

\subsection{Traitement}

Toute découverte d'un nouveau cancer bronchique doit faire suite à une présentation en Réunion de Concertation Pluridisciplinaire (RCP). En cas d'impossibilité, le patient doit être enregistré a posteriori dans un délai de 3 mois. La RCP nécessite la présence d'au moins trois des spécialistes suivants: un oncologue radiothérapeute, un pneumologue ou un oncologue médical si le pneumologue n'a pas cette qualification, un chirurgien, un spécialiste en imagerie et un pathologiste.

\subsubsection{Stades IV}

Le traitement de référence repose sur la chimiothérapie. Même si ce cancer est chimiosensible, il ne permet qu'exceptionnellement une survie supérieure à 2 ans (2\%). Sans traitement, la survie est estimée entre 3 à 6 mois. Avec un traitement, la médiane de survie varie de 9 à 14 mois (en fonction des études et protocoles étudiés) avec une nette amélioration de la qualité de vie.

\subsubsection{1. $\quad 1^{\text {ère }}$ ligne}

Le taux de réponse objective est de 60 à $75 \%$ après $1^{\text {ère }}$ ligne dans le cadre d'un stade IV. Le traitement de référence est l'association du cisplatine $(80$ à $100 \mathrm{mg} / \mathrm{m} 2$ à $\mathrm{J} 1)$ à l'étoposide (VP16 : 80 à 120mg/m2 à J1, J2, J3)(7,8). Entre les années 1980 et 1990, de nombreux essais ont été réalisés pour éviter les chimio résistances secondaires (par exemple de nouveaux schémas de chimiothérapie ou des intensifications de dose) mais il n'a été mis en évidence qu' une majoration de la toxicité, sans bénéfice sur la survie.

Une étude comparant l'association PCDE (cisplatine, cyclophosphamide, épirubicine, étoposide) avec cisplatine-étoposide a permis de retrouver une amélioration significative du taux de réponse et de survie avec le PCDE (9). Le problème de cette association est l'excès de 
décès toxiques observés chez les patients avec un performance statut (PS) à 2. Ce protocole est donc uniquement à réserver aux patients en bon état général (PS $=0$ ou 1$)$ et sous couvert de facteurs de croissance.

Plusieurs essais se sont intéressés à l'association cisplatine-irinotécan comparée à cisplatineétoposide. Notamment un essai japonais retrouvait un allongement de survie significatif. (10) Par contre, un essai Nord-Américain comparable n'a, lui, pas mis en évidence de différence significative.(11)

En cas de contre-indication au cisplatine, le carboplatine à la dose de 5 AUC (Calvert) semble pouvoir être utilisé sans perte de chance notamment chez les patient âgés ou fragiles.(12)

Les cycles de chimiothérapie sont réalisés toutes les 3 semaines pour un nombre total de 4 à 6 cycles. Il semblerait que l'essentiel du bénéfice soit obtenu à la phase d'induction. (Figure 2)

Après réponse partielle ou complète, l'intérêt de réaliser une chimiothérapie au delà de 6 cycles n'est pas démontré. En effet, dans la revue systématique de treize essais randomisés publiée par Sculier et al., un seul essai a montré une différence statistiquement significative sur la survie en faveur de la maintenance et cinq études n'ont montré un avantage de survie que dans certains sous-groupes de patients. Une étude a observé une survie significativement plus courte avec le traitement de maintenance, et six études n'ont objectivé aucune différence.

Il n'existe pas de thérapie ciblée pour le moment. (essai négatif avec le Bevacizumab - Essai IFCT - en cours de publication). Le thalidomide a été testé pour ses propriétés antiangiogéniques mais une toxicité trop importante était retrouvée et sans bénéfice de survie. $(14,15)$ 


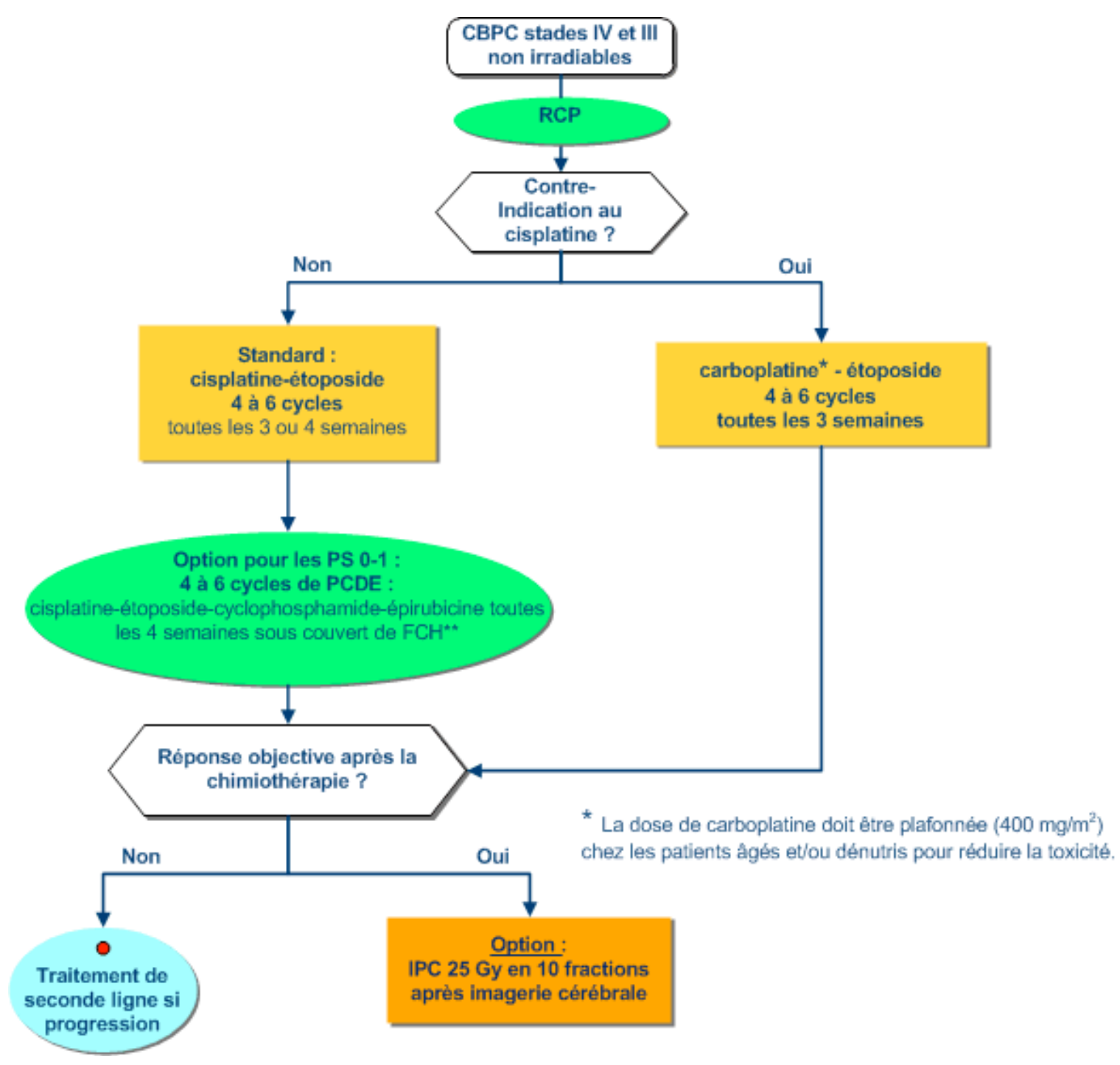

Figure 2: Arbre décisionnel dans le cadre du traitement du CBPC en $1^{\text {ère }}$ ligne de chimiothérapie chez les patients ayant un statut initialement disséminé. (16)

1.8.1.2. $\quad 2^{\text {ème }}$ ligne

Bien que les taux de réponse au traitement de première ligne soient très élevés, une progression survient dans environ $95 \%$ des cas, dans les 12 mois après la chimiothérapie pour les stades limités et dans les 4 mois après la chimiothérapie pour les CBPC disséminés. Le but des traitements de seconde ligne est d'allonger la survie mais surtout d'apporter une palliation des symptômes avec une amélioration de la qualité de vie. Les rechutes sont le plus souvent exclusivement traitées par chimiothérapie. 
Les patients qui rechutent après une réponse initiale sont classés en 4 groupes : (6)

- «très sensibles » si la rechute survient plus de 6 mois après l'arrêt de la chimiothérapie de première ligne,

- «sensibles» si la rechute survient entre 3 et 6 mois après l'arrêt de la chimiothérapie de $1^{\text {ère }}$ ligne,

- «résistants» en cas de rechute avant 3 mois,

- « réfractaires » en cas de progression sous traitement.

Chez les patients «très sensibles» et «sensibles», le schéma par chimiothérapie par cisplatine ou carboplatine associé à l'étoposide peut être repris. (17) Les dernières recommandations de l'American College of Chest Physicians proposent la réintroduction de la chimiothérapie initiale dans les progressions survenant au-delà de 6 mois après la fin du traitement de première ligne. (6)

Les patients « résistants » ou « réfractaires » bénéficient d'une chimiothérapie de deuxième ligne, qui dépend de l'état du patient, de la réponse à la première ligne et de ses comorbidités. Il n'existe pas de standard mais plusieurs options thérapeutiques sont possibles (Figure 3) :

- Topotécan en intraveineux $\left(1,5 \mathrm{mg} / \mathrm{m}^{2}\right.$ de $\mathrm{J} 1$ à $\mathrm{J} 5$ tous les 21 jours ou 3 à $4 \mathrm{mg} / \mathrm{m}^{2}$ à $\mathrm{J} 1, \mathrm{~J} 8$, $\mathrm{J} 15$ et reprise à $\mathrm{J} 28$ )

- Topotécan en per os $\left(2,3 \mathrm{mg} / \mathrm{m}^{2}\right.$ de $\mathrm{J} 1$ à $\mathrm{J} 5$ tous les 21 jours $)$

- CAV (cyclophosphamide à $500 \mathrm{mg} / \mathrm{m}^{2}$, adriamycine à $50 \mathrm{mg} / \mathrm{m}^{2}$, vincristine à $1,4 \mathrm{mg} / \mathrm{m}^{2}$ )

- CEV (cyclophosphamide à $1000 \mathrm{mg} / \mathrm{m}^{2}$, épirubicine à $60 \mathrm{mg} / \mathrm{m}^{2}$, vincristine à $1 \mathrm{mg} / \mathrm{m}^{2}$ )

- Carboplatine-paclitaxel (possible après discussion en RCP).

Chez les patients « réfractaires », il n'existe pas non plus de standard et le traitement doit être discuté en RCP.

Une étude a comparé la chimiothérapie de $2^{\text {ème }}$ ligne aux soins de support. Cette comparaison portait sur le topotécan per os versus les soins de support quand la chimiothérapie intraveineuse n'était pas possible. Dans cette étude, près de la moitié des patients étaient « sensibles » et un PS inférieur à 2. La médiane de survie était de 5,9 mois sous topotécan versus 3,2 mois pour les soins de support. (18) 
Une étude a comparé le topotécan versus le CEV chez les patients ayant rechutés à plus de 60 jours. On observe une meilleure tolérance du topotécan mais une absence de différence significative sur la survie sans progression et sur la survie globale. (19)

L'amrubicine qui est une anthracycline de $3^{\text {ème }}$ génération a été évaluée dans plusieurs études notamment versus le topotécan. Une étude de phase III retrouvait chez les patients « sensibles» une médiane de survie de 9,2 mois pour l'amrubicine et de 9,9 mois pour le topotécan et chez les patients « réfractaires », respectivement à 6,2 mois et 5,7 mois. $(20,21)$

Néanmoins une étude récente n'a pas retrouvé d'amélioration significative en terme de survie globale entre le topotécan et l'amrubicine en deuxième ligne. Il existait une amélioration non significative chez les patients « réfractaires » traités avec amrubicine.(22)

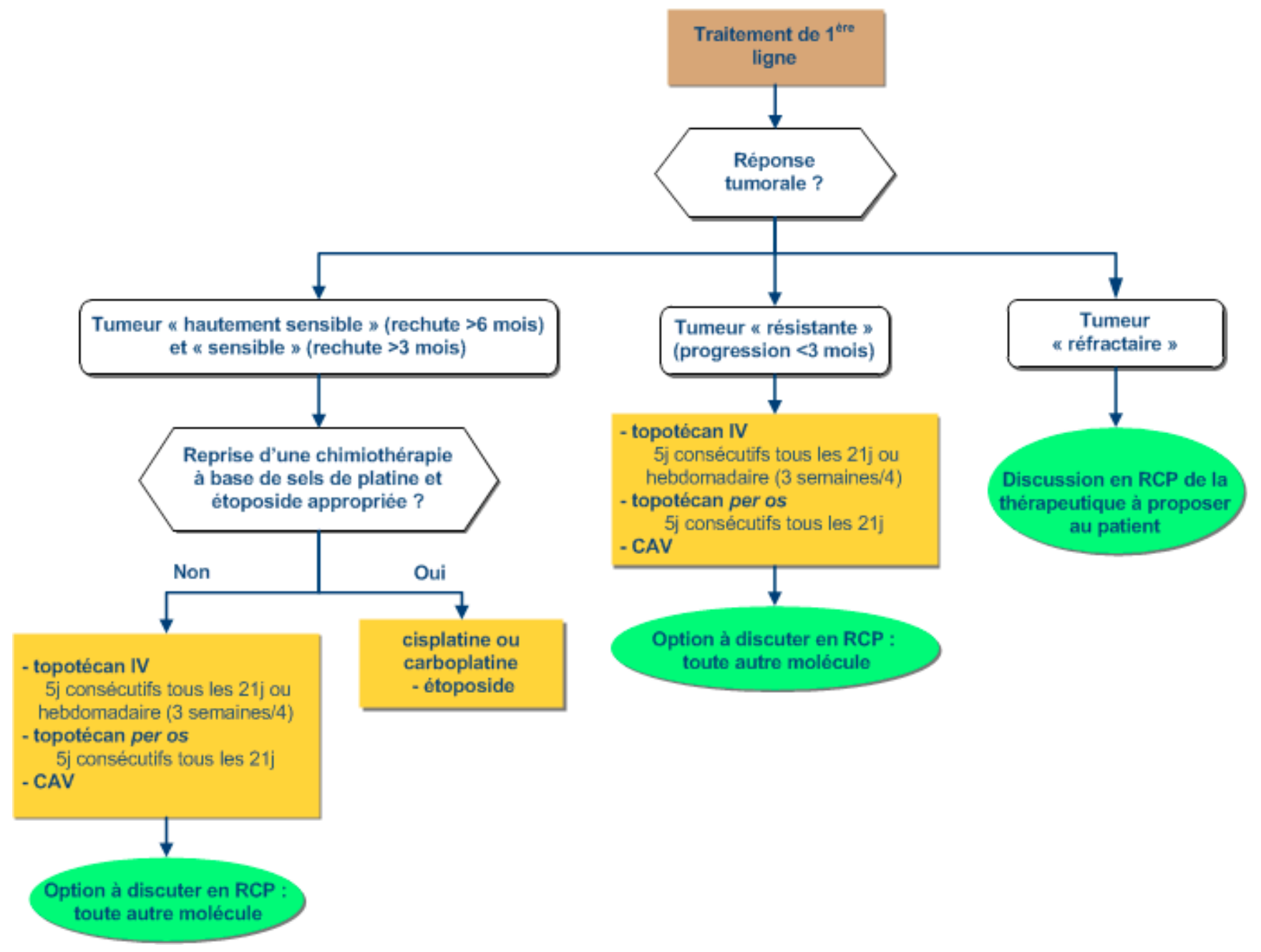

Figure 3 : Arbre décisionnel dans le cadre du traitement du CBPC en $2^{\text {ème }}$ ligne de chimiothérapie. (16) 


\subsubsection{Localisé}

Le traitement des cancers à petites cellules de stade I à III repose sur l'association d'une chimiothérapie et d'une radiothérapie thoracique (RT-CT) (Figure 4). Chez ces patients, la survie est estimée entre 15 et $25 \%$ à 5 ans.

Le traitement préconisé consiste en une association d'une chimiothérapie de 4 cures et d'une radiothérapie thoracique concomitante (au minimum 60 Grays) avec un fractionnement conventionnel. Chez les patients âgés ou ayant un PS supérieur à 2, une association séquentielle peut être envisagée.

Il est préconisé d'introduire de manière précoce la radiothérapie concomitante, si possible dans les 30 jours après le début de la chimiothérapie. (24) L'augmentation de la dose biologique de radiothérapie permet une amélioration de l'efficacité du traitement. Turrisi et al. ont démontré sur 381 patients ayant eu une RT-CT (cisplatine-étoposide) avec radiothérapie concomitante de 45 Gy en schéma accéléré avaient un meilleur taux de survie à 2 et 5 ans. (25) Une étude prospective a comparé la radiothérapie du volume tumoral initial avec la radiothérapie du volume post-induction, il n'a pas été mis en différence significative. (26)

En effet, plusieurs études ont montré la supériorité de la RT-CT sur la chimiothérapie seule au stade localisé. Pignon et al. retrouvent une réduction globale du risque de décès de $14 \%$, un bénéfice en terme de survie globale à 3 ans de 5,4\% et un meilleur contrôle de la maladie au niveau local. (23)

Arriagada et al. ont démontré l'importance des doses initiales de chimiothérapie en comparant 2 groupes de patients recevant le même protocole de chimiothérapie à des doses différentes. Le $1^{\text {er }}$ groupe a reçu du cisplatine à $100 \mathrm{mg} / \mathrm{m} 2$ et du cyclophosphamide à $300 \mathrm{mg} / \mathrm{m} 2$ pendant 4 jours de suite, et le second du cisplatine à $80 \mathrm{mg} / \mathrm{m} 2$ et du cyclophosphamide à $225 \mathrm{mg} / \mathrm{m} 2$ pendant 4 jours de suite. (27) Les doses de doxorubicine et d'étoposide étaient identiques dans les 2 groupes. Le taux de survie à 2 ans pour les 55 patients traités par les plus hautes doses de chimiothérapie était de $43 \%$ comparé à $26 \%$ pour les 50 patients ayant reçu des doses plus faibles $(p=0,02)$ avec également un moins bonne survie sans progression. (28) 


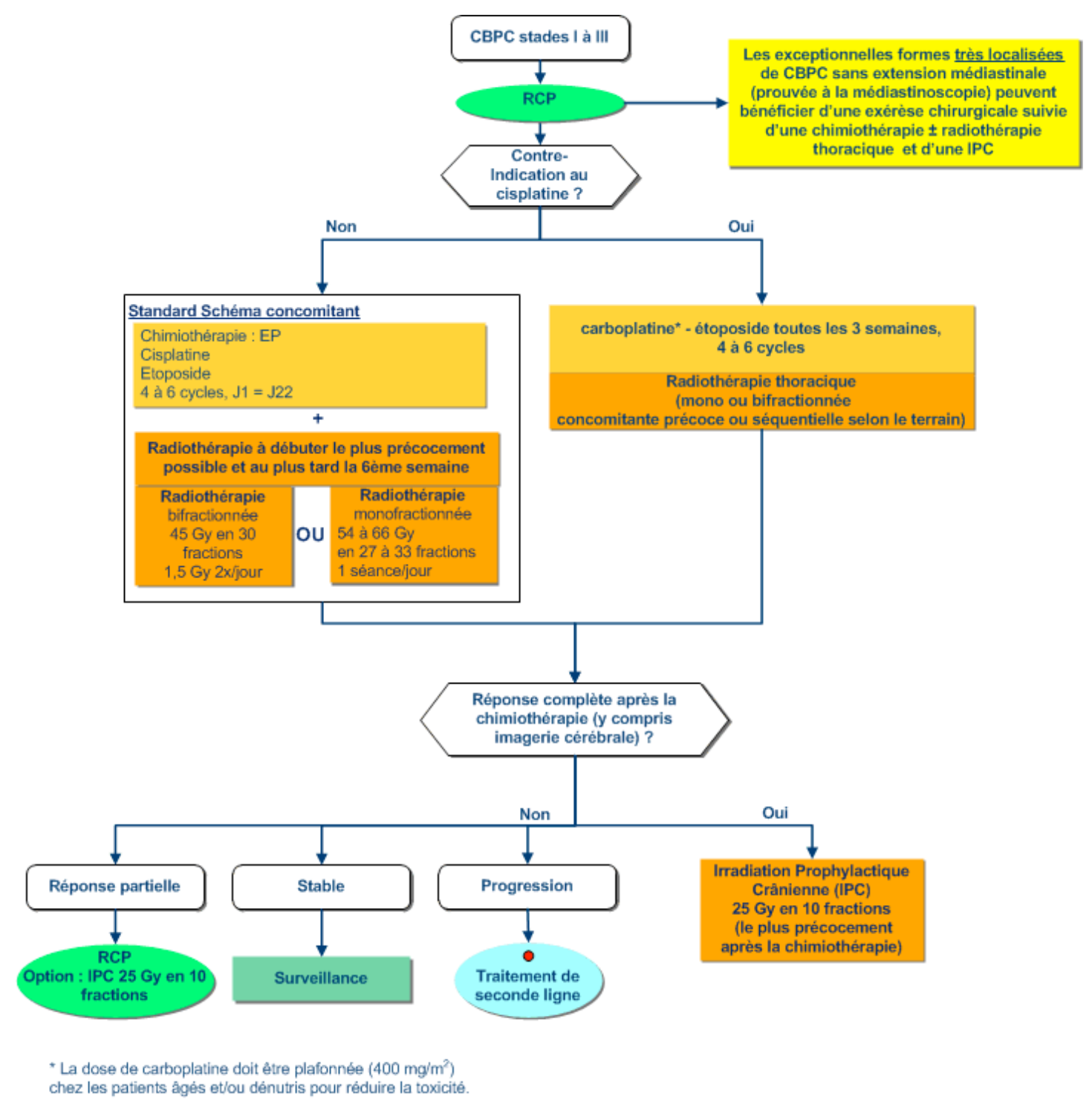

Figure 4 : Arbre décisionnel dans le cadre du traitement du CBPC en $1^{\text {ère }}$ ligne de chimiothérapie chez les patients ayant un statut initialement localisé. (16)

\subsubsection{Radiothérapie}

La radiothérapie thoracique est également possible dans le CBPC disséminé. Notamment lorsque la localisation primitive est en réponse objective et que l'ensemble des sites extrathoraciques est en réponse complète.

Il existe 3 types d'associations :

- séquentielle lorsque la radiothérapie et la chimiothérapie sont administrées de manière séparée,

- alternée lorsque la radiothérapie est délivrée entre les cures de chimiothérapie,

- concomitante lorsque la chimiothérapie et la radiothérapie sont délivrées en même temps. 
Un essai a comparé RT-CT séquentielle versus concomitante dans les CBPC limités. La médiane de survie à 3 ans est meilleure dans le bras concomitant (29,8\% vs 20,2\%) ainsi que la médiane de survie (27,2 mois vs 19,7 mois). Mais ces résultats ne sont pas statistiquement significatifs. (29). Une étude a également comparée RT-CT alternée versus séquentielle et on ne retrouve pas de différence significative.(30,31)

Une étude sur 109 patients a comparé un schéma comprenant 3 cycles de cisplatine-étoposide puis 4 cycles de la même chimiothérapie avec un schéma comprenant 2 carboplatineétoposide avec radiothérapie concomitante et 2 nouveaux cycles de cisplatine. Le bras avec RT-CT retrouve une survie à 5 ans de $9,1 \%$ versus $3,7 \%$. (32)

\subsubsection{Intérêt de l'irradiation cérébrale prophylactique.}

Le CBPC est le seul sous-groupe dans les cancers bronchiques où l'IPC a démontré une amélioration de la survie. Il est important de signaler que 15 à $20 \%$ des patients atteints de CBPC ont des métastases cérébrales au moment du diagnostic. Concernant les patients indemnes de métastases cérébrales, 20 à $40 \%$ risque d'en développer à 1 an.(33,34) Ces données ont permis de mettre en avant le concept de l'Irradiation Prophylactique Cérébrale (IPC).

Une méta-analyse étudiant l'IPC chez les patients présentant une réponse complète, notamment avec une maladie localisée initiale, a démontré que l'IPC réduisait le risque de récidive cérébrale d'environ $50 \%$ avec un gain de survie sans progression de $25 \%$ ( $\mathrm{p}=0,001)$. (35)

Une étude randomisée de l'EORTC a montré le bénéfice de l'IPC chez les patients présentant un $\mathrm{CBPC}$ étendu en réponse après chimiothérapie en diminuant le risque cumulé de métastases cérébrales à 1 an de 40,4\% à 14,6\% et en augmentant la survie globale par rapport au bras sans radiothérapie. (33) Il est donc recommandé de proposer une IPC chez les patients en réponse d'un CBPC localisé ou disséminé, à la dose de 25 Gy en 10 fractions. (33) 


\subsubsection{Chirurgie}

Il existe très peu d'indications opératoires dans les CBPC. Cela est lié à leur potentiel évolutif et métastatique élevé. Fox et al. a publié un essai comparant la radiothérapie et la chirurgie. Dans cet essai, la survie à 2 ans était de $4 \%$ dans le cadre de la chirurgie et $10 \%$ dans le cadre de la radiothérapie.(36)

Un essai randomisé avait étudié, la présence ou non d'une chirurgie après 5 cures de chimiothérapie avec réalisation d'une radiothérapie thoracique et encéphalique dans les 2 bras. La médiane de survie était plus faible dans le bras chirurgie mais sans résultat significatif. La chirurgie n'a donc pas été développée dans les formes limitées. $(37,38)$ Lorsqu'on s'intéresse aux patients opérés à un stade précoce et diagnostiqués à postériori de la chirurgie comme étant un CBPC, le taux de survie est meilleur que dans le groupe non opéré. (39) La place de la chirurgie est donc floue et reste encore à préciser dans les stades précoces. La chirurgie, associée à une chimiothérapie adjudante, doit néanmoins être discutée dans les stades I après un bilan d'extension complet sans envahissement ganglionnaire ou extra-thoracique.

\subsubsection{Soins de support}

L'utilisation dès la première cure de chimiothérapie de G-CSF est optionnelle en prophylaxie primaire et recommandée en prophylaxie secondaire. En cas de facteurs de risque de neutropénie (notamment avec un PS supérieur à 2), hypo-albuminémie, âge élevé, envahissement médullaire, antécédent de cancer traité, lymphocytes $<0.7$ giga/l, l'utilisation de G-CSF en prophylaxie primaire est recommandée.

L'ASCO en 2006 recommande de ne pas utiliser le G-CSF durant l'association radiochimiothérapie. Une étude de phase III a comparé l'administration ou non de G-CSF associé à une radio-chimiothérapie standard. Le groupe facteurs de croissance a présenté plus de thrombopénies sévères et plus de décès toxiques mais moins de neutropénies de grade 4 que dans le groupe contrôle.(40)

L'utilisation d'un agent stimulant l'érythropoiése (ASE) est utile pour améliorer la qualité de vie des patients dès la chute du taux d'hémoglobine inférieure ou égale à $10 \mathrm{~g} / \mathrm{dL}$, avec un taux cible à $12 \mathrm{~g} / \mathrm{dL}$. Le traitement doit être suspendu ou modifié au-delà̀ de $12 \mathrm{~g} / \mathrm{dL}$. L'utilisation d'un ASE doit être réservée aux patients traités par chimiothérapie. 


\subsection{Pronostic}

Les facteurs pronostiques pré-thérapeutiques favorables connus sont le stade I à III, le PS à 0 ou 1 et le sexe féminin. La survie sans traitement est d'environ 3 mois, elle est estimée à $14 \%$ à 5 ans (13\% chez l'homme et $18 \%$ chez la femme) et à $9 \%$ à 10 ans ( $9 \%$ chez l'homme et $12 \%$ chez la femme).

Il n'existe à l'heure actuelle aucune méthode clairement validée pour le dépistage du CBPC. La meilleure arme pour lutter contre la survenue du cancer des poumons et de la mortalité associée à cette pathologie reste la prévention, en agissant en particulier contre le tabagisme. 


\section{Matériel et Méthode}

\subsection{Méthodologie de l'étude}

\subsubsection{Type d'étude}

Il s'agissait d'une étude observationnelle rétrospective chez les patients atteints d'un cancer bronchique à petites cellules ayant bénéficié d'une $2^{\text {ème }}$ ligne de chimiothérapie au CHU d'Amiens et au CH de Saint-Quentin entre 2004 et 2014.

\subsubsection{Aspect réglementaire et éthique}

Il s'agit d'une étude non interventionnelle sans impact sur la prise en charge des patients inclus dans l'étude. Compte tenu du caractère rétrospectif, du mauvais pronostic de la pathologie étudiée et du grand nombre de patients décédés au moment du recueil de données, il a été difficile de prévenir les patients de l'utilisation de leurs données. Une demande pour être présentée en CEERNI auprès de la Direction de la Recherche Clinique du CHU d'Amiens a été réalisée.

\subsubsection{Objectifs et critères de jugement}

L'objectif principal de l'étude était de comparer 3 protocoles (paclitaxel-topotécan, topotécan seul, CEV) de chimiothérapie en $2^{\text {ème }}$ ligne dans le cadre du CBPC entre 2004 et 2014 au CH de St Quentin et au CHU d'Amiens.

Le critère de jugement principal était la survie sans progression (SSP) après la $2^{\text {ème }}$ ligne de chimiothérapie.

Les objectifs secondaires étaient :

- Evaluer l'impact du PS en $1^{\text {ère }}$ et $2^{\text {ème }}$ ligne sur la SSP après la $2^{\text {ème }}$ ligne de chimiothérapie ainsi que son évolution au cours du traitement.

- Evaluer l'impact de la présence de métastase cérébrale (initialement et apparue en 1ère ligne) sur la SSP après la $2^{\text {ème }}$ ligne de chimiothérapie.

- Evaluer l'impact du statut initial (localisé ou disséminé) au moment du diagnostic sur la SSP après la $2^{\text {ème }}$ ligne de chimiothérapie.

- Evaluer l'impact du protocole choisi sur la survie globale. 
- Evaluer l'impact des patients étiquetés «résistants» en $1^{\text {ère }}$ ligne sur la survie sans progression après la $2^{\text {ème }}$ ligne de chimiothérapie.

- Evaluer l'impact du PS en début de $2^{\text {ème }}$ ligne de chimiothérapie sur le choix du protocole de $2^{\text {ème }}$ ligne.

- Evaluer l'impact des différents effets indésirables des différents protocoles de chimiothérapie sur la SSP après la $2^{\text {ème }}$ ligne de chimiothérapie.

- Evaluer le type de réponse en fonction de chaque protocole après la $2^{\text {ème }}$ ligne de chimiothérapie.

- Evaluer la survie sans progression et la survie globale de l'ensemble de la population étudiée.

- Evaluer l'impact de la radiothérapie de type prophylactique cérébrale et de la radiologie palliative sur la SSP après la $2^{\text {ème }}$ de chimiothérapie.

\subsubsection{Sélection de la population :}

Les critères d'inclusion sont :

- Tous les patients atteints de CBPC ayant bénéficié d'au moins 3 cures en $1^{\text {ère }}$ ligne et en échec de réponse et de 2 cures au moins de chimiothérapies avec bilan de réévaluation en $2^{\text {ème }}$ ligne de traitement.

- Au CHU d'Amiens et au CH de Saint-Quentin

- Entre 2004 et 2014

Etaient exclus les patients n'ayant bénéficié que d'une seule cure de chimiothérapie en $2^{\text {ème }}$ ligne. Le recrutement des patients a été réalisé dans les 2 centres à partir d'une base de données informatiques et des archives papiers des patients atteints d'un cancer bronchopulmonaire.

\subsubsection{Les données recueillies : (annexe 1)}

- Données concernant le patient: âge, sexe, centre, motif de découverte, tabagisme, comorbidités.

- Les données concernant la $1^{\text {ère }}$ ligne :

- Le PS en début de $1^{\text {ère }}$ ligne ;

- Le statut initial au moment du diagnostic: localisé ou disséminé. En cas de statut disséminé : la localisation des métastases ;

- La présence d'une radiothérapie pulmonaire ; 
- La présence d'une IPC ;

- Le nombre total de chimiothérapies par CDP-VP16, carboplatine ou cisplatine et les doses choisies (AUC 5 ou 6 ) ;

- La présence d'une chimiothérapie par PCDE pendant la $1^{\text {ère }}$ ligne ;

- Les réductions de dose de $0 \%, 20$ à $25 \%$ ou 40 à $50 \%$.

- La résistance à la $1^{\text {ère }}$ ligne : les patients «résistants» étaient définis par ceux en progression à 3 ou à 6 mois et les stables à 3 cures ;

- Les lieux de rechute ou de progression: hépatique, cérébrale, surrénale, osseuse, pulmonaire ou autre ;

- Les données concernant la $2^{\text {ème }}$ ligne :

- Le PS en début et fin de $2^{\text {ème }}$ ligne ;

- Le type de protocole : paclitaxel-topotécan, topotécan seul, CEV ou CAV ;

- Les dates des $1^{\text {ères }}, 2^{\text {èmes }}$ et $3^{\text {èmes }}$ cures ;

- La présence d'effets indésirables $\geq$ grade 2 et le type et à partir de quelle cure ils sont apparus ;

- Les reports de cure ;

- La dose de chimiothérapie ;

- La réduction de dose de $0 \%$, de 20 à $25 \%$ ou de 40 à $50 \%$ et à partir de quelle cure celle-ci a été appliquée ;

- La présence d'une radiothérapie palliative et l'organe cible ;

- L'évolution après la $2^{\text {ème }}$ ligne et le type avec les sites de métastases ;

- La décision de RCP après la $2^{\text {ème }}$ ligne ;

- La date de progression;

- La date de décès ;

\subsubsection{Protocoles de chimiothérapie}

Les 2 centres avaient des protocoles de chimiothérapie similaires.

$$
\text { 2.1.6.1. } 1^{\text {ère }} \text { ligne : }
$$

Les protocoles utilisés en $1^{\text {ère }}$ ligne étaient :

- Cisplatine à la dose initiale de $80 \mathrm{mg} / \mathrm{m}^{2}$ associé à l'étoposide à la dose de $120 \mathrm{mg} / \mathrm{m}^{2}$.

- Carboplatine à une AUC de 5 ou 6 selon Calvert associé à l'étoposide à $120 \mathrm{mg} / \mathrm{m}^{2}$.

- PCDE (Cisplatine, cyclophosphamide, doxorubicine, étoposide) 


\subsubsection{2. $2^{\text {ème }}$ ligne :}

Les protocoles utilisés en $2^{\text {ème }}$ ligne étaient :

- Topotécan en monothérapie : $1,5 \mathrm{mg} / \mathrm{m}^{2}$ en intraveineux ou $2,3 \mathrm{mg} / \mathrm{m}^{2}$ en per os.

- Topotécan associé au paclitaxel aux posologies respectives de $1 \mathrm{mg} / \mathrm{m}^{2}$ et de 135 $\mathrm{mg} / \mathrm{m}^{2}$.

- CEV aux posologies de $1000 \mathrm{mg} / \mathrm{m}^{2}$ pour le cyclophosphamide, $60 \mathrm{mg} / \mathrm{m}^{2}$ pour l'épirubicine et $1 \mathrm{mg} / \mathrm{m}^{2}$ pour le vincristine.

- CAV aux posologies de $500 \mathrm{mg} / \mathrm{m}^{2}$ pour le cyclophosphamide, $50 \mathrm{mg} / \mathrm{m}^{2}$ pour l'adriamycine et de $1,4 \mathrm{mg} / \mathrm{m}^{2}$ pour le vincristine.

Les effets indésirables étaient classés selon la classification OMS des effets toxiques aigus et subaigus des traitements anti-cancéreux (Annexe 4). Le PS était évalué en fonction des critères OMS (Annexe 2).

\subsection{Analyse statistique}

Une analyse descriptive de la population a été faite, les variables quantitatives sont présentées en moyenne et écart type et les qualitatives en fréquence et pourcentage. Les facteurs prédictifs de la prise en charge du choix de la deuxième ligne ont été recherchés en bivarié grâce au Chi2 de Pearson ou le test exact de Fisher en fonction de la distribution pour les variables qualitatives et par le test de Student ou le test de Wilcoxon en fonction de la distribution pour les variables quantitatives.

La survie globale et la survie sans progression de la population ont été évaluées selon la méthode de Kaplan Meier. Le critère de jugement pour la survie globale était le décès et pour la survie sans progression: le premier évènement progression ou décès. La date de « endpoint » était pour la survie globale la première date entre date de décès, la date des dernières nouvelles ou celle du 15 juillet 2015. Pour la survie sans progression, il s'agissait de la première date parmi la date de progression, la date de décès, la date des dernières nouvelles ou celle du 15 juillet 2015. Les médianes de survie ont ensuite été comparées selon différents facteurs correspondant soit au terrain soit à des variables attachées à la première ligne ou des variables concernant la deuxième ligne. La comparaison a été faite grâce au test du log rank. Un p inférieur à 0,05 est considéré comme significatif. Les analyses ont été faites grâce au logiciel SPSS 18.0. 


\section{Résultats}

\subsection{Description de la population et évaluation des pratiques}

\subsubsection{Description de la population}

Entre janvier 2004 et décembre 2014, 62 patients ont pu avoir un bilan de réévaluation après la $2^{\text {ème }}$ ligne. La répartition des effectifs entre les 2 centres était équivalente avec un effectif de 32 patients pour le CHU d'Amiens (soit 51,6\%) et 30 patients pour le CH de St Quentin (Soit 48,4\%) (Figure 5). La majorité des patients étaient de sexe masculin avec 44 hommes soit $71 \%$ contre 18 femmes soit $29 \%$. La quasi-totalité des patients ont eu un tabagisme (56 patients soit $98,2 \%)$.

Plus de la moitié des patients n'avaient pas de comorbidité au moment du diagnostic (34 soit $54,8 \%)$. Le motif de découverte était une manifestation clinique pour 45 patients $(75 \%)$ dont la majorité des manifestations était une hémoptysie, une découverte fortuite pour 10 patients $(16,7 \%)$, un syndrome paranéoplasique pour 3 patients $(5 \%)$ et un dépistage pour 2 patients $(3,3 \%)$.

Au diagnostic, 23 patients avaient un statut localisé $(37,1 \%)$ et 39 patients $(62,9 \%)$ un statut disséminé (Figure 5). Parmi les patients avec un statut disséminé, 16 patients (57,9\%) avaient des métastases hépatiques, 13 des métastases cérébrales (soit 34,2\%), 12 des métastases osseuses $(31,6 \%), 5$ des métastases surrénaliennes (13,2\%), 2 des métastases pulmonaires $(5,3 \%)$ et 6 des métastases autres $(15,8 \%)$.

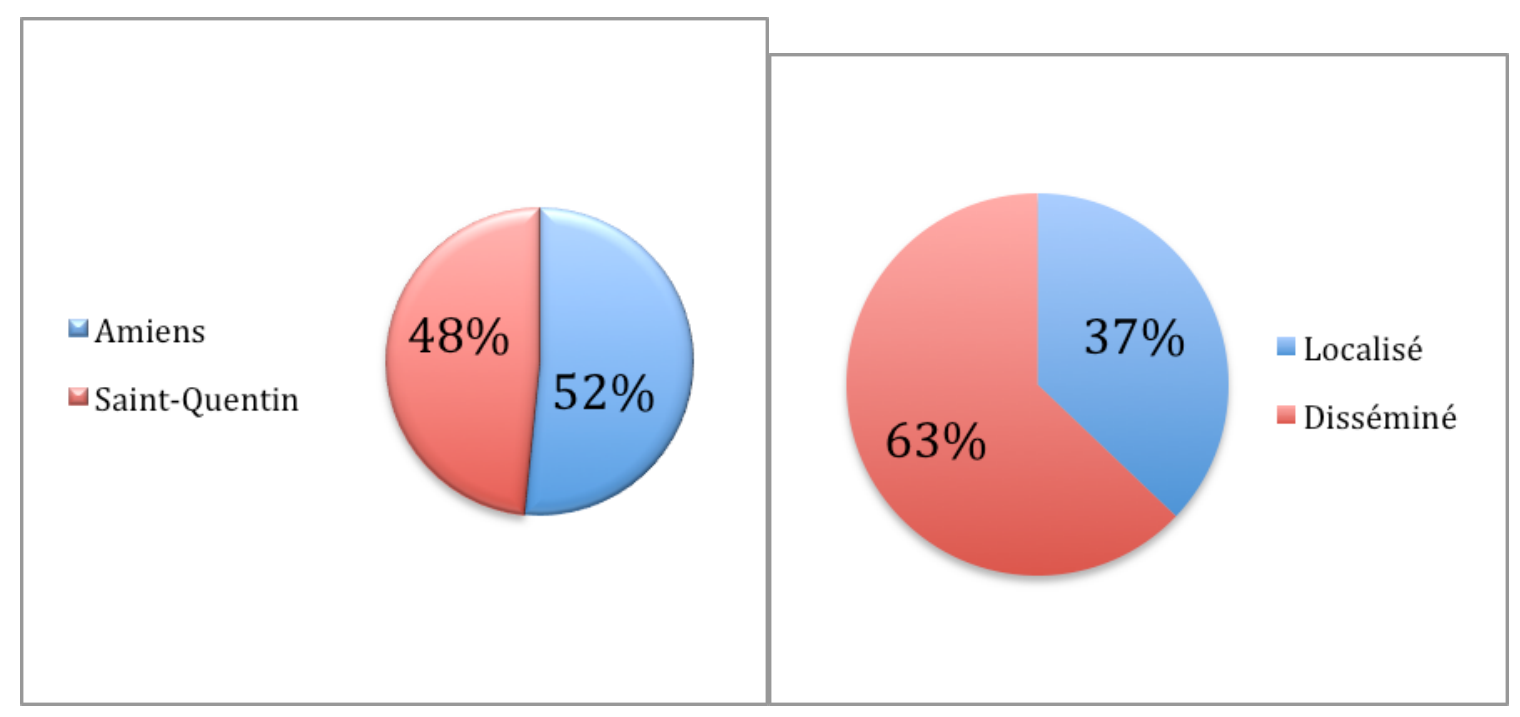

Figure 5 : Répartition de la population entre les 2 centres (à gauche). Statut initial de la maladie au diagnostic (à droite). 


\subsubsection{Résultats descriptifs de la $1^{\text {ère }}$ ligne}

Le performance statut (PS) en début de $1^{\text {ère }}$ ligne était strictement inférieur à 2 pour 54 patients $(93,1 \%)$. Seuls 4 patients $(6,9 \%)$ avaient un PS supérieur ou égal à 2. Parmi les patients avec un PS à $0,42 \%$ étaient localisés.

Tous les patients bénéficiaient de chimiothérapie par sels de platine et étoposide, 16 patients $(25,8 \%)$ ont bénéficié de plus de 6 cures du doublet et 46 patients $(74,1 \%)$ ont eu 6 cures ou moins en $1^{\text {ère }}$ ligne. Trente patients $(48,3 \%)$ ont bénéficié uniquement de chimiothérapie par cisplatine, 15 patients $(24,1 \%)$ ont eu uniquement une chimiothérapie par carboplatine et 17 patients $(27,4 \%)$ ont eu des alternances entre cisplatine et carboplatine. Huit patients $(12,9 \%)$ ont eu au cours de leur $1^{\text {ère }}$ ligne au moins une cure de chimiothérapie par PCDE. Quarantecinq patients $(73,8 \%)$ n'ont pas eu de réduction de dose, 21,3\% (13 patients) ont eu une réduction de dose entre 20 et $25 \%$ et $4,9 \%$ (3 patients) une réduction de dose de 40 à $50 \%$.

Vingt-cinq patients $(41 \%)$ ont bénéficié de radiothérapie pulmonaire en $1^{\text {ère }}$ ligne (pour rappel, 23 patients étaient localisés au moment du diagnostic). Un seul patient a bénéficié d'une chirurgie thoracique.

Après la $1^{\text {ère }}$ ligne, 36 patients $(58,1 \%)$ ont été considérés comme « réfractaires » (moins de 3 mois de réponse après la $1^{\text {ère }}$ ligne), 20 patients $(32,3 \%)$ comme « sensibles » (moins de 6 mois de réponse après la $1^{\text {ère }}$ ligne) et 6 patients $(9,7 \%)$ comme «très sensibles » (rechute après plus de 6 mois de réponse). Une résistance a été retrouvée chez 32 patients $(51,6 \%)$ (stabilisation à 3 cures, en progression à 3 et 6 cures). Les sites de progression ou de rechute étaient par ordre de fréquence : pulmonaire, hépatique, cérébrale, osseuse et surrénalienne (Tableau I).

\subsubsection{Résultats descriptifs de la $2^{\text {ème }}$ ligne}

En $2^{\text {ème }}$ ligne, 24 patients soit $38,7 \%$ ont eu une chimiothérapie par topotécan seul, 22 patients soit $35,5 \%$ ont eu une chimiothérapie par paclitaxel-topotécan et 16 patients soit $25,8 \%$ ont eu une chimiothérapie par CAV ou CEV (Figure 6).

L'âge des patients en début de $2^{\text {ème }}$ ligne était inférieur à 65 ans pour 45 patients $(72,6 \%)$, entre 65 ans et 75 ans pour 11 patients $(17,7 \%)$ et supérieur ou égal à 75 ans pour 6 patients $(9,7 \%)$. 


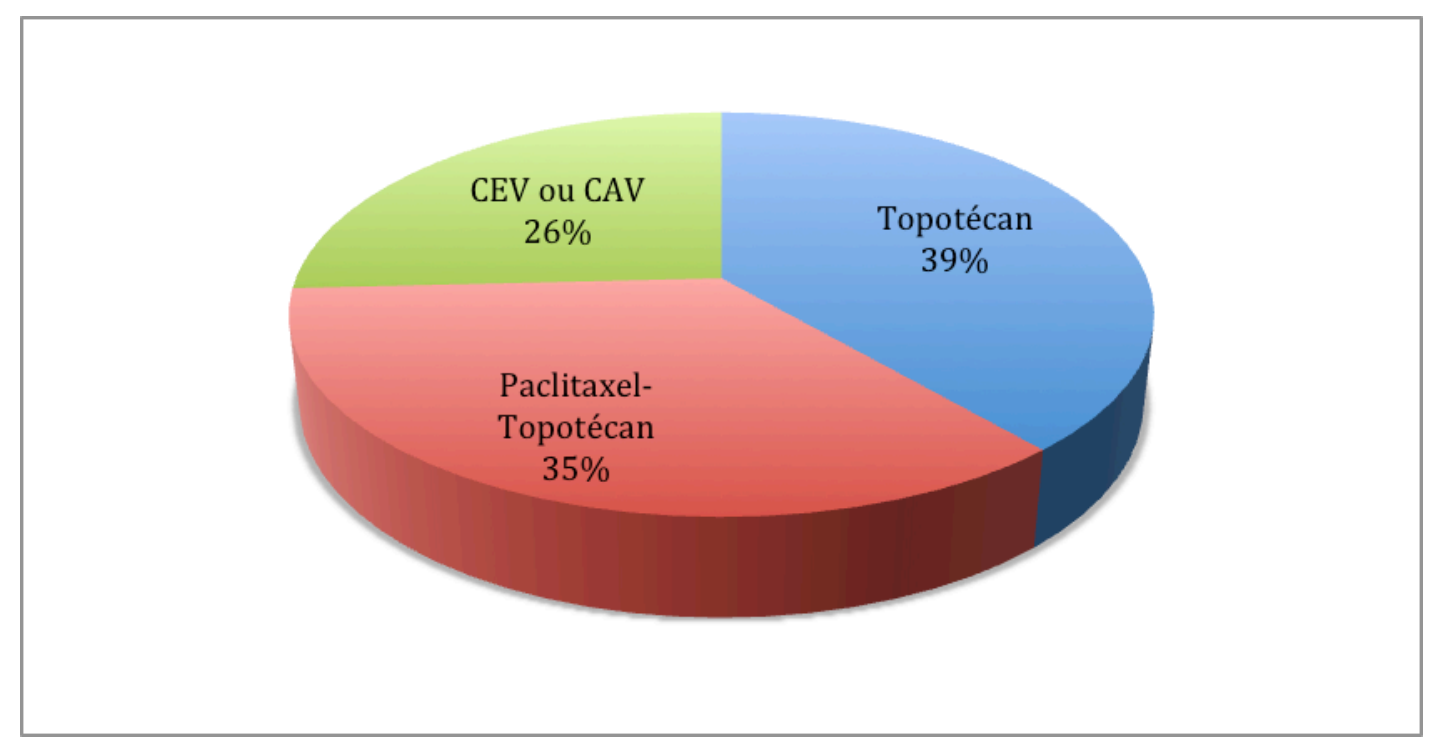

Figure 6 : Répartition des différents protocole de chimiothérapie en $2^{\text {ème }}$ ligne

Quarante-trois patients $(69,4 \%)$ ont eu des effets indésirables de stade 2 ou supérieur. Ils sont apparus après la $1^{\text {ère }}$ cure pour 22 patients $(52,4 \%)$, après la $2^{\text {ème }}$ cure pour 13 patients $(30,9 \%)$ et après la $3^{\text {ème }}$ cure pour 7 patients $(16,7 \%)$. Les effets indésirables postchimiothérapie, tous protocoles confondus, sont par ordre de fréquence: thrombopénie, asthénie, anémie, neutropénie, anorexie, vomissement, diarrhée, autre (Figure 7). Parmi les 62 patients inclus, 15 ont eu un report de cure $(24,2 \%)$. Trente-sept patients $(60,7 \%)$ n'ont pas eu de réduction de dose, 22 patients (36\%) ont eu une réduction de dose comprise entre 20 et $25 \%$ de la dose initiale et 2 patients $(3,3 \%)$ ont eu une réduction de dose de 40 et $50 \%$ de la dose initiale en $2^{\text {ème }}$ ligne.

$\mathrm{Au}$ moment du bilan de réévaluation, 7 patients soit $11,3 \%$ ont eu une réponse partielle ou complète, 19 étaient en stabilisation soit $30,6 \%$ et 36 patients étaient en progression soit $58,1 \%$. Pour les patients en progression, 34 patients soit 94,4\% une progression à distance. Les sites de progression étaient au niveau cérébral pour 20 patients $(57,1 \%$ des patients en progression), pulmonaire pour 18 patients (50\%), hépatique pour 9 patients (soit 25,7\%), osseux pour 6 patients $(17,1 \%)$, surrénalien pour $5(14,3 \%)$, et autre pour 6 patients $(17,1 \%)$ (Tableau I).

Le PS en début de $2^{\text {ème }}$ ligne était inférieur à 2 pour 45 patients $(77,6 \%)$ et supérieur ou égal à 2 pour 13 patients $(22,4 \%)$. Après 2 ou 3 cures en $2^{\text {ème }}$ ligne, il était inférieur à 2 pour 37 patients $(61,7 \%)$ et égale ou supérieur à 2 pour 23 patients $(38,3 \%)$. 
La décision de RCP après réévaluation de la $2^{\text {ème }}$ ligne de chimiothérapie a été pour 28 patients $(45,2 \%)$ le passage en $3^{\text {ème }}$ ligne, pour 19 patients $(30,6 \%)$ la poursuite de la même chimiothérapie, pour 15 patients une surveillance radio-clinique $(24,2 \%)$ devant une altération importante de l'état général.

\begin{tabular}{|c|c|c|}
\hline & $1^{\text {ère }}$ ligne (\%) & $2^{\text {ème }}$ ligne (\%) \\
\hline PULMONAIRE & $50 \%$ & $50 \%$ \\
\hline HEPATIQUE & $27,8 \%$ & $25,7 \%$ \\
\hline CEREBRALE & $25,9 \%$ & $57,1 \%$ \\
\hline OSSEUSE & $20,4 \%$ & $17,1 \%$ \\
\hline SURRENALIENNE & $16,7 \%$ & $14,3 \%$ \\
\hline
\end{tabular}

Tableau I : Sites de progression ou rechute en fonction de la ligne de chimiothérapie.

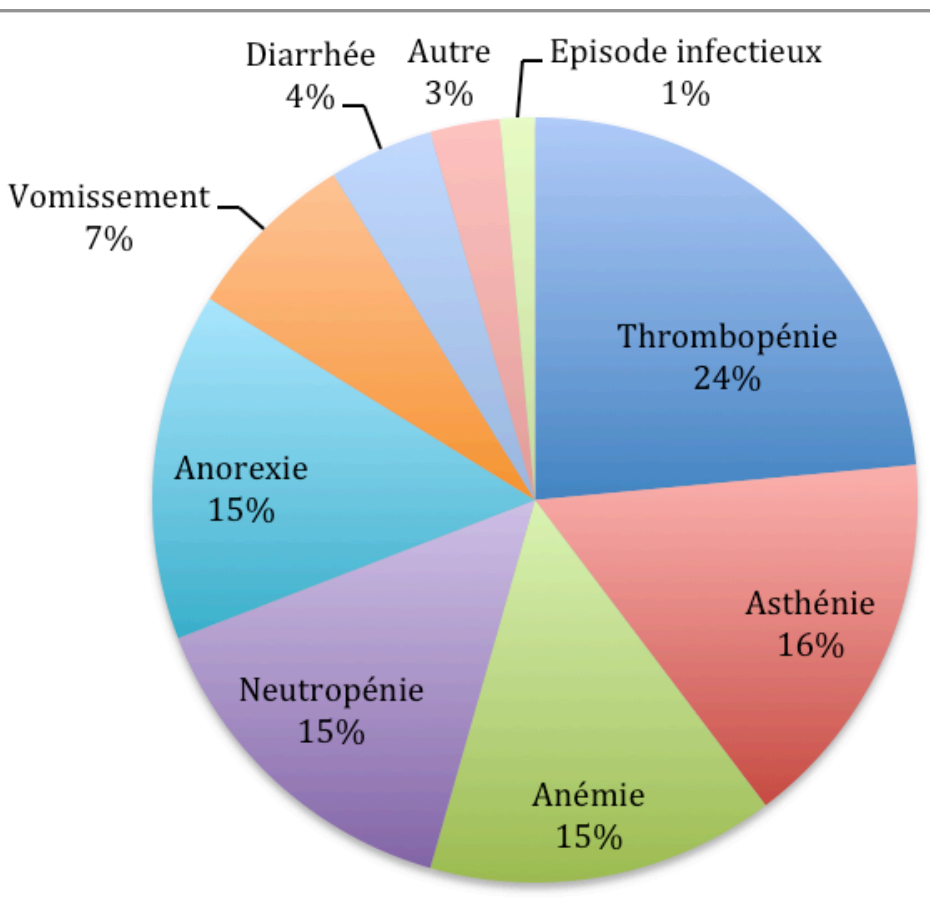

Figure 7 : Répartition des différents effets indésirables de grade 22 (classification OMS) en $\underline{2}^{\text {ème }}$ ligne de chimiothérapie tous protocoles confondus. 


\subsection{Evaluation du critère de jugement principal}

On ne retrouve pas de différence significative en terme de survie sans progression quand on compare les différents protocoles de deuxième ligne : topotécan seul, paclitaxel-topotécan et CEV ou CAV avec des médianes respectives de 3,34 mois, 3,57 mois et 3,11 mois ( $\mathrm{p}=$ 0,824). (Figure 8)

\begin{tabular}{|c|c|c|}
\hline Protocole & $\begin{array}{c}\text { Médiane } \\
\text { de survie } \\
\text { (mois) }\end{array}$ & Odds Ratio ; IC 95\% \\
\hline Topotécan & 3,34 & OR $=0,42 ;$ IC 95\% $[2,51-4,17]$ \\
\hline $\begin{array}{c}\text { Paclitaxel- } \\
\text { Topotécan }\end{array}$ & 3,57 & OR $=0,53 ;$ IC 95\% $[2,51-4,62]$ \\
\hline CEV ou CAV & 3,11 & OR $=0,49 ;$ IC 95\% $[2,15-4,07]$ \\
\hline
\end{tabular}

Tableau II : Médiane de Survie sans progression des différents protocoles de chimiothérapie.

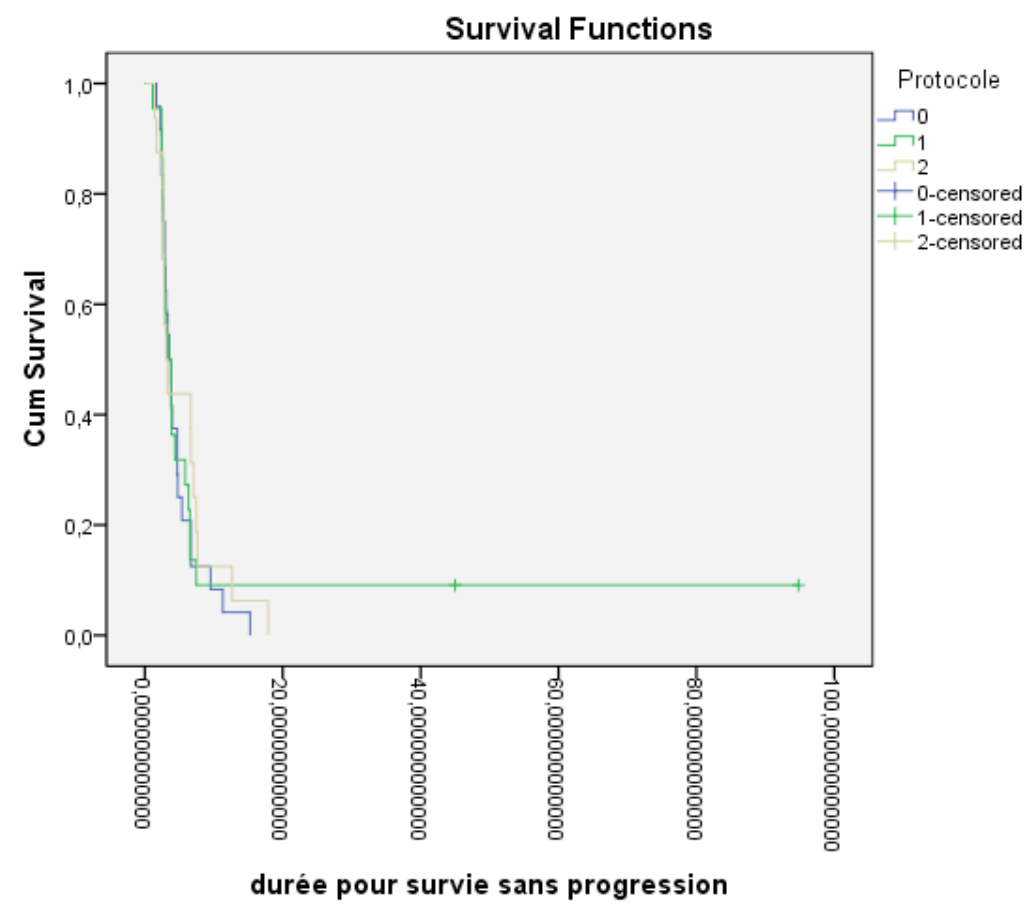

Figure 8: Survie sans progression en mois des différents protocoles de chimiothérapie. 0) Topotécan ; 1) Paclitaxel-Topotécan ; 2) CEV ou CAV. 


\subsection{Critères de jugement secondaires}

\subsubsection{Survie sans progression et Survie Globale.}

Dans notre étude, la médiane de survie sans progression est de 3,34 mois (OR $=0,282$; IC 95\% [2,792-3,896] et la médiane de survie globale estimée à 8,6 mois $(\mathrm{OR}=0,910$; IC 95\% $[6,817-10,383])$.

\subsubsection{Survie globale en fonction du protocole choisi}

Tout comme pour la survie sans progression, il n'existe pas différence significative de la survie globale en mois en fonction des différents protocoles choisis $(p=0,422)$. Les médianes de survies globales sont de 10,00 mois (OR = 1,445 ; IC 95\% [7,168-12,832]) pour paclitaxeltopotécan, 9,63 mois (OR =2,386 ; IC 95\% [4,957-14,309]) pour CEV ou CAV et 8,50 mois $(\mathrm{OR}=0,990$; IC 95\% [6,56-10,44]) pour le topotécan seul. On ne retrouve pas différence significative entre les 2 centres étudiés $(p=0,229)$. Les médianes de survie sans progression sont de 3,02 mois $(\mathrm{OR}=0,278$; IC 95\% [2,471-3,562]) pour Amiens et 3,90 mois (OR = 0,611 ; IC 95\% [2,705-5,098]) pour Saint-Quentin.

\subsubsection{Impact du statut initial : disséminé ou localisé?}

On retrouve une meilleure survie sans progression de manière significative $(p=0,043)$ chez les patients qui étaient localisés au moment du diagnostic initial par rapport à ceux qui avaient un statut disséminé avec des médianes respective de 3,11 mois (OR $=0,169$; IC 95\% [2,783$3,446])$ et 4,36 mois $(\mathrm{OR}=0,550$; IC 95\% [3,283-5,438])

\subsubsection{Concernant la $1^{\text {ère }}$ ligne}

\subsubsection{1. $\quad$ Présence de métastase cérébrale}

La présence de métastase cérébrale au moment du diagnostic n'est pas un facteur influençant la survie sans progression avec une médiane estimée à 2,78 mois $(\mathrm{OR}=0,55$; IC 95\% [1,71$3,86])$ contre 3,11 mois ( $\mathrm{OR}=0,19$; IC 95\% [2,74-3,49]) en l'absence de métastase cérébrale

$(p=0,592)$. Il en est de même lorsque la rechute ou la progression en cours de $1^{\text {ère }}$ ligne se situe au niveau cérébral, avec une médiane de survie sans progression qui passe de 3,34 mois $(\mathrm{OR}=0,415 ; \mathrm{IC} 95 \%[2,531-4,157])$ à 2,88 mois $(\mathrm{OR}=0,491 ; \mathrm{IC} 95 \%$ [1,923-3,847] $)$ en cas de progression au niveau cérébrale $(\mathrm{p}=0,271)$. L'apparition de métastase cérébrale en $1^{\text {ère }}$ ligne n'est pas retrouvé non plus comme un facteur pronostic de la survie sans progression qui 
passe de 3,57 mois $(\mathrm{OR}=0,381$; IC 95\% [2,826-4,321]) à 2,88 mois $(\mathrm{OR}=0,157$; IC 95\% [2,577-3,193]) lors de l'apparition de métastase cérébrale $(p=0,157)$. (Figure 9)

3.3.4.2. Evaluer si la réponse en $1^{\text {ère }}$ ligne à un impact sur la survie sans progression

Lorsqu'on s'intéresse à la résistance à la chimiothérapie en $1^{\text {ère }}$ ligne, (incluant les patients en progression à 3 et 6 mois et la stabilité à 3 mois), on retrouve une différence non significative en terme de survie sans progression $(\mathrm{p}=0,08)$. En effet, la médiane passe de 3,80 mois (OR $=0,416 ; \mathrm{IC} 95 \%[2,987-4,620])$ à 2,88 mois $(\mathrm{OR}=0,224 ; \mathrm{IC} 95 \%[2,445-3,325])$ chez les patients « résistants » (Figure 10). Il n'y a pas différence significative en terme de survie sans progression entre les patients ayant reçu en $1^{\text {ère }}$ ligne, 6 cures ou moins du doublet sel de platine associé à l'étoposide par rapport aux patients ayant reçu plus de 6 cures $(p=0,459)$.

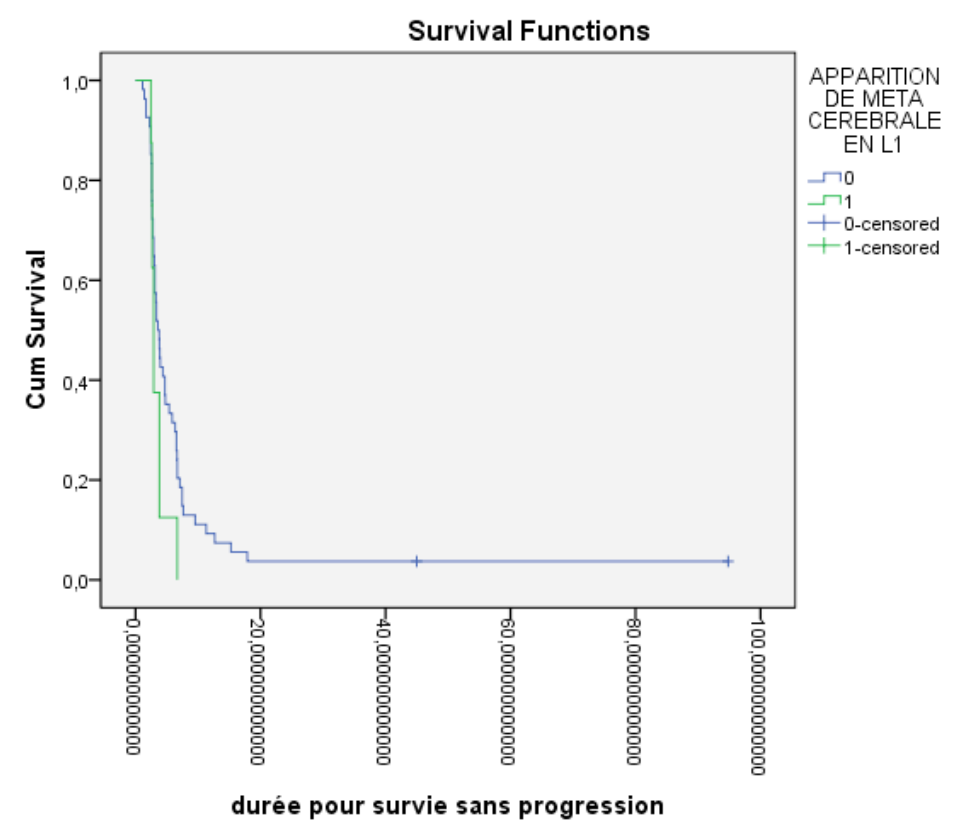

Figure 9 : Survie sans progression en mois en fonction de l'apparition de métastase cérébrale en $\underline{1^{\text {ère }}}$ ligne. 


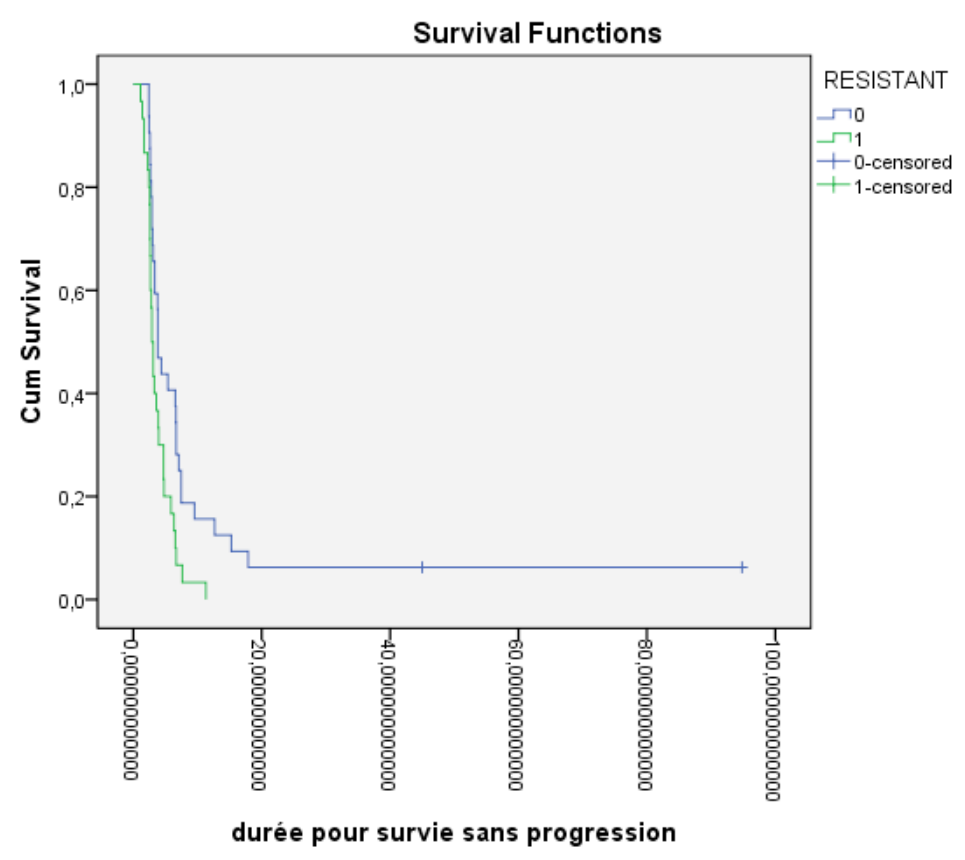

Figure 10 : Survie sans progression en mois en fonction du statut « Résistant» en $1^{\text {ère }}$ ligne de chimiothérapie.

\subsubsection{Concernant la $2^{\text {ème }}$ ligne}

\subsubsection{Réponse initiale de chaque protocole en $2^{\text {ème }}$ ligne}

Parmi les patients ayant bénéficié de la chimiothérapie par topotécan seul, 8,3\% des patients étaient en réponse partielle ou complète, $20,8 \%$ stables et $70,8 \%$ en progression au moment du bilan de réévaluation après la $2^{\text {ème }}$ ligne de chimiothérapie (soit après 2 ou 3 cures de chimiothérapie de $2^{\text {ème }}$ ligne).

Avec le protocole paclitaxel-topotécan, 13,6\% étaient en réponse partielle ou complète, $36,4 \%$ en stabilité et $50 \%$ en progression.

Parmi les 16 patients ayant bénéficiés du protocole CEV ou CAV, 12,5\% étaient en réponse partielle ou complète, $37,5 \%$ en stabilité et $50 \%$ en progression (Figure 12).

Il a été mis en évidence que la réponse initiale en $1^{\text {ère }}$ ligne influence le type de réponse en $2^{\text {ème }}$ ligne. Parmi les patients « réfractaires » en $1^{\text {ère }}$ ligne, $5,6 \%$ ont répondu en $2^{\text {ème }}$ ligne, $25 \%$ étaient stables et $69,4 \%$ en progression. En ce qui concerne les patients «sensibles », $25 \%$ ont répondu, $50 \%$ étaient stables et $25 \%$ en progression. (Figure 11 )

On ne retrouve pas de modification significative de la survie globale chez les patients ayant comme site de progression la localisation cérébrale $(\mathrm{p}=0,89)$. 


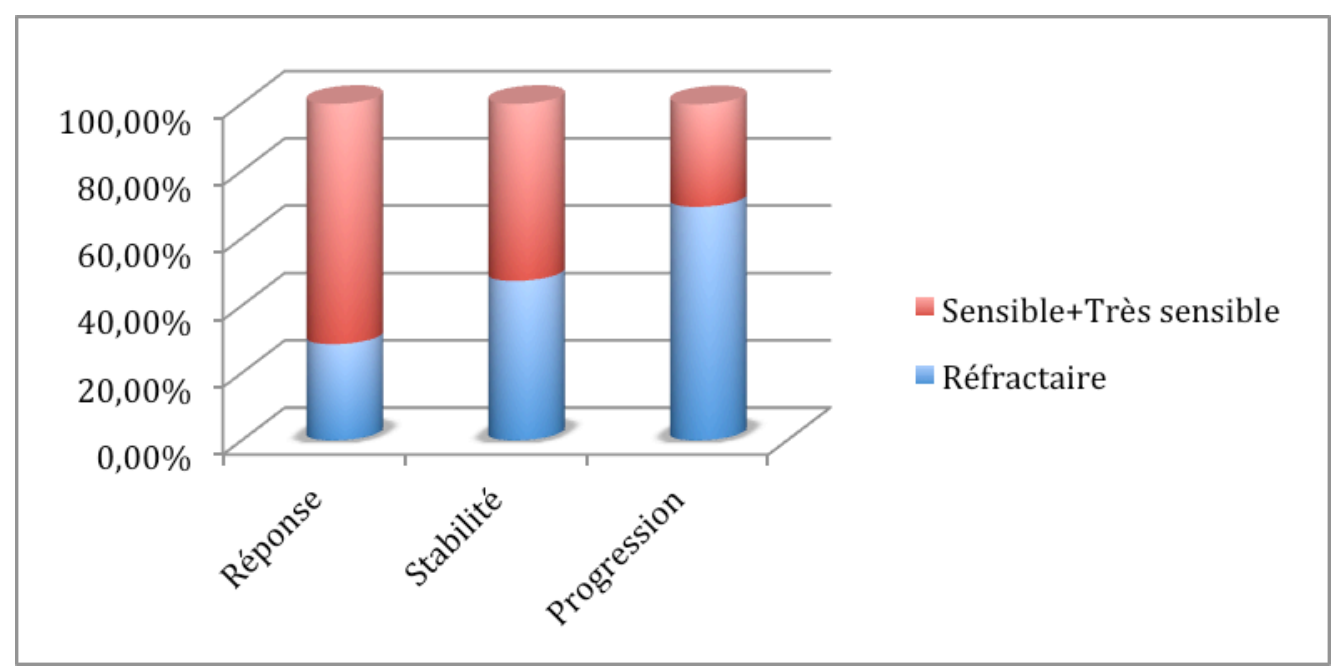

Figure 11 : Réponse en $2^{\text {ème }}$ ligne de chimiothérapie chez les patients « Très sensibles », «Sensibles » et « Réfractaires » en $1^{\text {ère }}$ ligne de chimiothérapie.

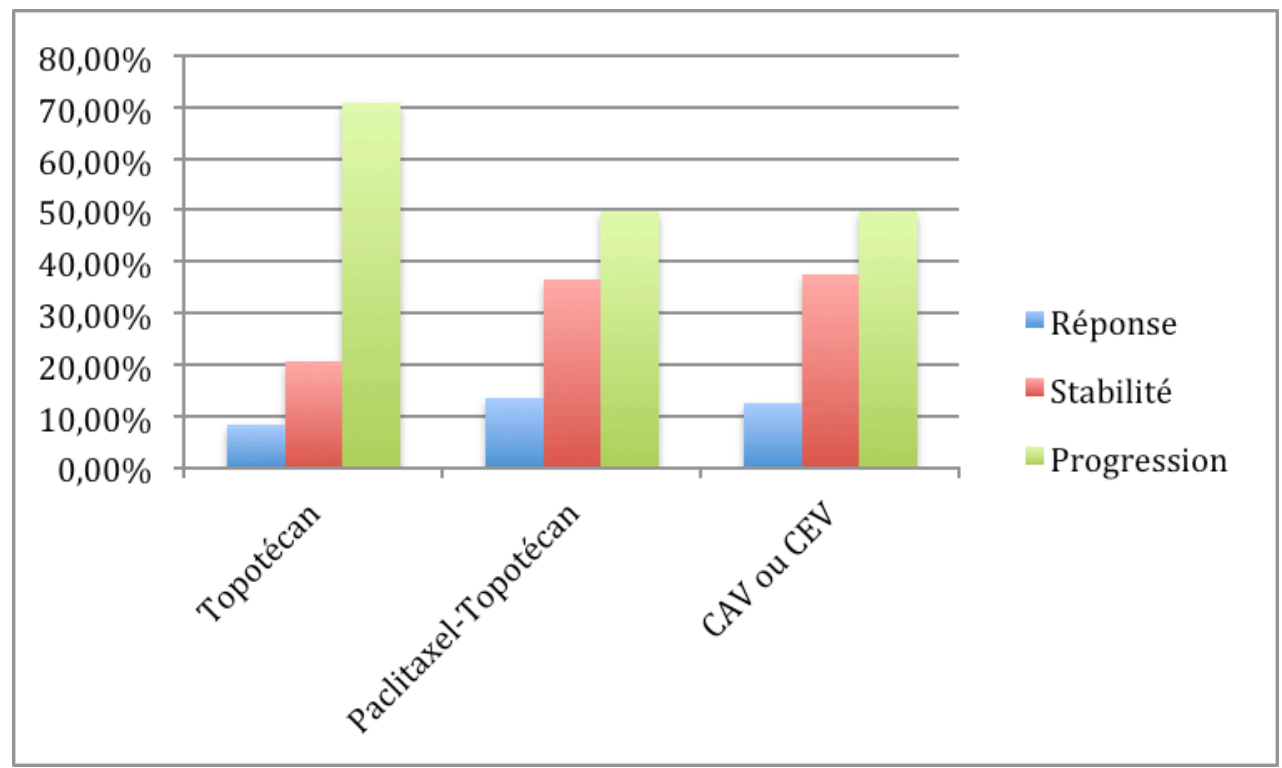

Figure 12 : Réponse au moment du $1^{\text {er }}$ bilan de réévaluation en $2^{\text {ème }}$ ligne de chimiothérapie en fonction des 3 protocoles étudiés.

\subsubsection{Evaluation de l'impact du PS}

Le PS en début de $1^{\text {ère }}$ ligne n'est pas un facteur pronostic en terme de survie sans progression $(\mathrm{p}=0,792)$. Les patients avec un PS $<2$ ont une médiane de survie à 3,27 mois $(\mathrm{OR}=0,293$; IC $95 \%[2,705-3,852])$ versus 2,42 mois $(\mathrm{OR}=2,328$; IC 95\% [0-6,98)] pour les patients avec un PS $\geq 2$. On retrouve la même conclusion pour le statut PS en début de $2^{\text {ème }}$ ligne avec respectivement pour un PS $<2$ et un PS $\geq 2$ des médianes de survie sans progression à 3,34 mois $(\mathrm{OR}=0,311$; IC 95\% $[2,735-3,954])$ et 3,11 mois $(\mathrm{OR}=0,688$; IC 95\% $[1,767$ - 
4,462]) $(\mathrm{p}=0,699)$ (Figure 13). Il en est de même pour la survie globale $(\mathrm{p}=0,062)$.

Le PS de début de $2^{\text {ème }}$ ligne n'influence pas de manière significative le choix du protocole de chimiothérapie en $2^{\text {ème }}$ ligne $(\mathrm{p}=0,320)$. Chez les 21 patients avec un PS à 0,8 patients $(38,1 \%)$ ont bénéficié d'une chimiothérapie par paclitaxel-topotécan, 8 patients $(38,1 \%)$ par CEV ou CAV et 5 patients $(23,8 \%)$ par topotécan seul. Parmi les 24 patients avec un PS à 1 , 10 ont bénéficié d'une chimiothérapie par topotécan seul (41,7\%), 8 par paclitaxel-topotécan $(36,4 \%)$ et 6 par CEV ou CAV (25\%). Enfin parmi les 13 patients ayant un PS à 2, 6 patients ont eu topotécan seul $(46,2 \%), 6$ patients ont eu paclitaxel-topotécan $(46,2 \%)$ et 1 patient a eu CEV ou CAV (7,7\%) (Figure 14).

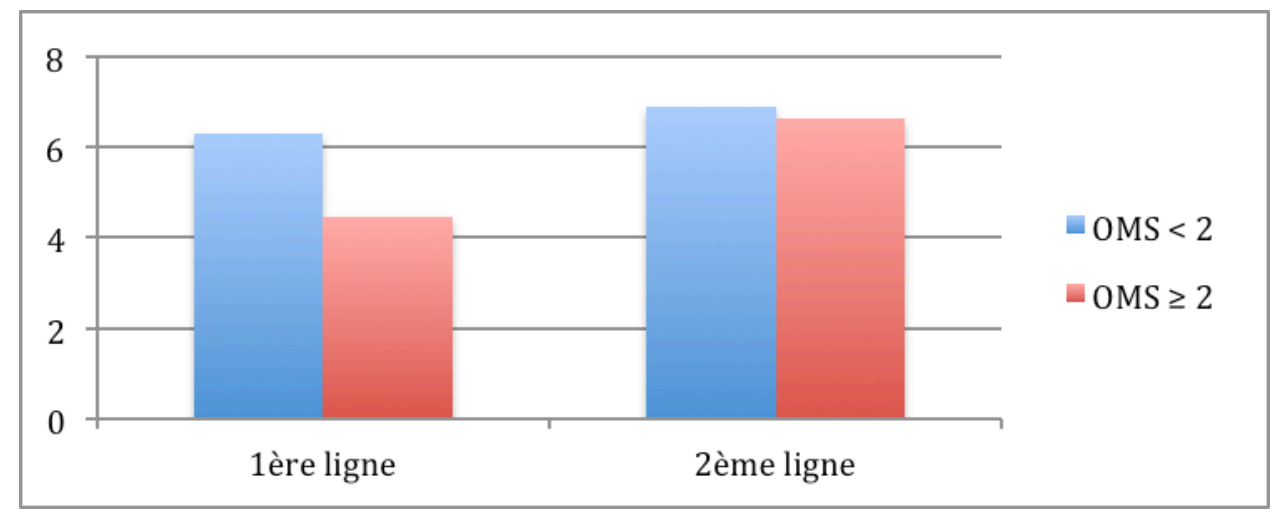

Figure 13 : Survie sans progression en mois en fonction du Statut OMS en $1^{\text {ère }}$ et $2^{\text {ème }}$ ligne de chimiothérapie.

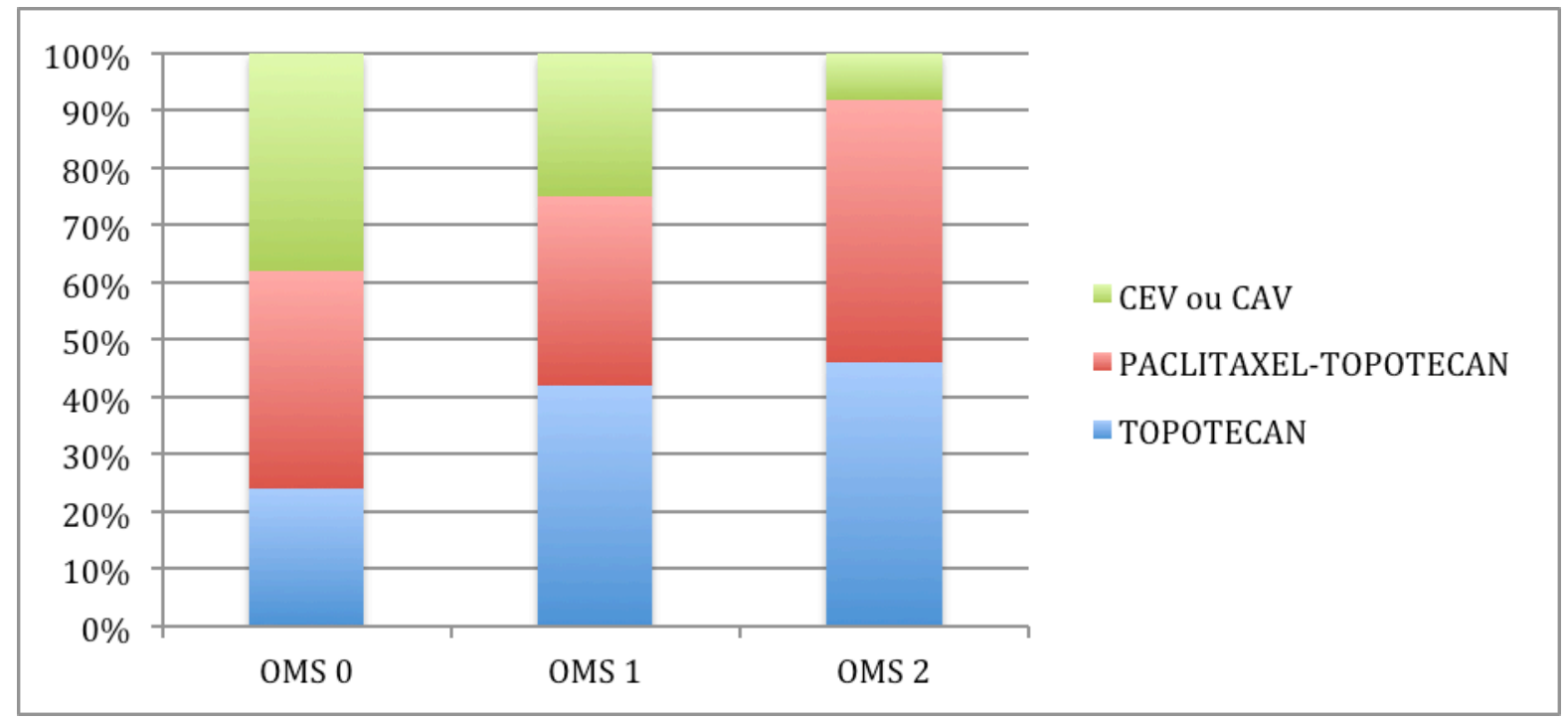

Figure 14 : Type de protocole de chimiothérapie choisi en fonction du statut OMS en début de $\underline{2}^{\text {ème }}$ ligne. 


\subsubsection{Evaluation des différents effets indésirables des protocoles de chimiothérapie}

On retrouve une différence significative entre les différents protocoles en ce qui concerne les effets indésirables de grade supérieur ou égal à $2(\mathrm{p}=0,032)$. Le pourcentage d'effets indésirables de grade supérieur ou égal à 2 de la classification OMS est respectivement pour le topotécan seul, le paclitaxel-topotécan et le CEV ou CAV, de 87,5\% (21 patients), 63,6\% (14 patients) et 50\% (8 patients) (Figure 15).

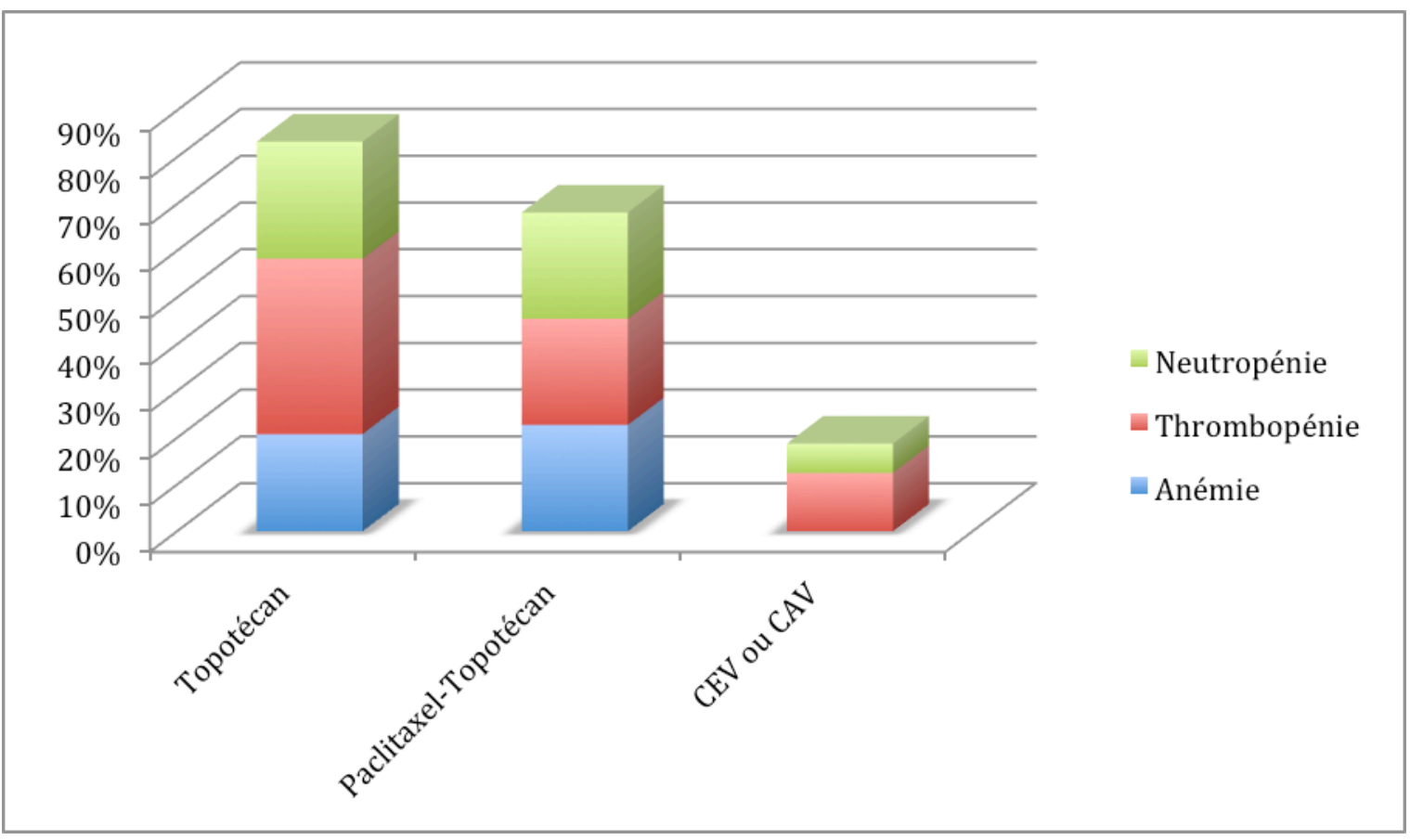

Figure 15: Effets indésirables sévères de grade 3 et 4 en fonction des différents protocoles de chimiothérapie.

\subsubsection{4. $\quad$ Place de la radiothérapie}

En $1^{\text {ère }}$ ligne, $32,7 \%$ des patients ont bénéficié d'une irradiation prophylactique cérébrale. $41 \%$ ont bénéficié d'une association radio-chimiothérapie. Il n'a pas été démontré de différence significative en terne de survie sans progression chez les patients ayant eu une IPC entre les patients ayant un statut disséminé ou localisé $(\mathrm{p}=0,463)$.

En $2^{\text {ème }}$ ligne, l'utilisation de la radiothérapie est moins importante. Seul 25,8\% des patients ont bénéficié d'une radiothérapie palliative. Parmi ces patients, 62,5\% (10 patients) avaient une irradiation cérébrale puis $12,5 \%$ au niveau osseux et médiastinal.

En $2^{\text {ème }}$ ligne, il n'a pas été mis en évidence de différence significative en terme de survie sans 
progression en fonction de la réalisation ou non d'une radiothérapie palliative $(p=0,608)$. Les médianes de survie sont estimées à 3,34 mois ( $\mathrm{OR}=0,389$; IC 95\% [2,582-4,107]) pour les patients n'ayant pas eu de radiothérapie palliative et à 3,11 mois $(\mathrm{OR}=0,689$; IC 95\% $[1,765-4,464])$ pour les patients ayant eu une radiothérapie palliative. On retrouve le même résultat en terme de survie globale avec des médianes qui passe de 8,6 mois (OR = 2,656; IC $95 \%[3,394-13,806])$ lorsqu'il existe l'utilisation de radiothérapie palliative à 9,4 mois (OR = 1,085 ; IC 95\% [7,273-11,527]) sans radiothérapie $(\mathrm{p}=0,996)$. 


\section{Discussion}

\subsection{Principaux résultats de l'étude}

Dans cette étude rétrospective, observationnelle, concernant la $2^{\text {ème }}$ ligne de chimiothérapie du CBPC, 62 patients ont pu être inclus entre 2004 et 2014 dans les centres d'Amiens et de Saint-Quentin.

Parmi les 3 protocoles, 38,7\% ont eu une chimiothérapie par topotécan seul, 35,5\% ont eu une chimiothérapie par paclitaxel-topotécan et $25,8 \%$ ont eu une chimiothérapie par CAV ou CEV. Il n'a pas été retrouvé de différence significative en terme de survie sans progression et de survie globale entre les différents protocoles.

On retrouve une différence significative entre les différents protocoles en terme d'effets indésirables (Grade $>$ ou $=2$ de la classification OMS). Avec par ordre de fréquence, le topotécan seul pour lequel $87,5 \%$ des patients ont présenté des effets indésirables de grade 2 ou plus, paclitaxel-topotécan $63,6 \%$ et CEV ou CAV $50 \%$.

Il a été mis en évidence que le type de réponse initiale en $1^{\text {ère }}$ ligne n'influence pas le type de réponse en $2^{\text {ème }}$ ligne (« réfractaires » ou «sensibles»). Même si parmi les patients « réfractaires » en $1^{\text {ère }}$ ligne, $5,6 \%$ ont répondu en $2^{\text {ème }}$ ligne, $25 \%$ étaient stables et $69,4 \%$ en progression. Il existe une différence significative en terme de survie sans progression en $2^{\text {ème }}$ ligne en fonction du statut localisé ou disséminé au moment du diagnostic.

En ce qui concerne, le PS en $1^{\text {ère }}$ et $2^{\text {ème }}$ ligne, il n'a pas été retrouvé d'influence en terme de survie sans progression. Nous n'avons pas mis en évidence de lien entre le PS en début de $2^{\text {ème }}$ ligne, et le choix du protocole de chimiothérapie de $2^{\text {ème }}$ ligne.

Les métastases cérébrales, qu'elles soient initiales, d'apparition en $1^{\text {ère }}$ ligne ou en $2^{\text {ème }}$ ligne, ne sont pas retrouvées comme un facteur de mauvais pronostic en terme de survie sans progression et survie globale.

La radiothérapie de type IPC en $1^{\text {ère }}$ ligne ou palliative en $2^{\text {ème }}$ ligne ne modifiait pas la survie sans progression.

\subsection{Limites de l'étude}

Notre étude est une étude de cohorte rétrospective sur 10 ans. Cette longue durée de prise en charge pourrait être reprochée car en 10 ans, dans le domaine médical, les prises en charge ont été amenées à changer. Mais cette longue période était nécessaire dans le cadre de cette étude 
rétrospective et au vu des critères d'inclusion fixés (patients ayant bénéficié d'au moins 2 cures en $2^{\text {ème }}$ ligne). La meilleure preuve est qu'il n'y a eu que 62 patients inclus.

Néanmoins, cette longue période n'est pas un réel problème en ce qui concerne les prises en charge du CBPC. En effet, celles-ci n'ont malheureusement pas beaucoup évolué ces dernières années.

Le recueil de données était réalisé à partir des dossiers papiers ou des bases informatiques de chaque centre. En ce qui concerne les données de radiothérapie, les services des 2 centres avaient leur propre base de données. Donc si la radiothérapie associée n'était pas décrite dans les courriers de pneumologie, l'information n'a pu être récoltée. Cela pourrait entrainer un biais de classement.

Par ailleurs, on pourra toujours rappeler la subjectivité concernant le PS qui est un biais de classement. Même si la classification est bien connue, elle reste subjective avec des différences inter-médecin. Ceci est d'autant plus visible dans notre étude qui montre que les patients avaient en majorité un bon PS (cela même en fin de $2^{\text {ème }}$ ligne). Mais il peut exister un biais de sélection. En effet, les patients n'ayant pas atteint au moins la $2^{\text {ème }}$ cure de chimiothérapie en $2^{\text {ème }}$ ligne étaient exclus. Cela laisse penser que ces patients avaient peutêtre un PS supérieur ou égal à 2 .

En ce qui concerne les effets indésirables biologiques, il peut exister également un biais de classement. Le nombre d'effets indésirables est probablement sous-estimé dans cette étude. Dans le cadre des effets indésirables fonctionnels type asthénie, nausées, vomissements, anorexie, ils n'étaient mentionnés que lorsqu'ils étaient graves. Pour les effets indésirables biologiques type anémie, thrombopénie et neutropénie, ils n'ont pu être répertoriés de manière totalement exhaustive car les patients ne bénéficiaient pas de bilans biologiques systématiques toutes les semaines mais uniquement avant chaque cure et en cas de problème particulier. Donc un effet indésirable biologique pouvait exister mais s'il n'était pas symptomatique, il n’était pas recensé.

\subsection{Tolérance de la chimiothérapie}

Contrairement à ce que l'on pourrait penser, la chimiothérapie semble être bien tolérée en $1^{\text {ère }}$ et $2^{\text {ème }}$ ligne. Le PS en est un marqueur représentatif, même si subjectif, de l'état général des patients en cours de traitement. En effet, les patients avec un PS $<2$ représentaient $93,1 \%$ en 
début de $1^{\text {ère }}$ ligne, $77,6 \%$ en début de $2^{\text {ème }}$ ligne et $61,7 \%$ en fin de $2^{\text {ème }}$ ligne. On ne perd que $16 \%$ de la population dans la catégorie « PS $<2 »$ entre le début et la fin de la 2 ème ligne.

Les reports de cure étaient minoritaires $(24,2 \%)$ et plus de la moitié de la population étudiée a pu bénéficier des cures de chimiothérapie à pleine dose (soit 60,66\%) durant leur $2^{\text {ème }}$ ligne. $\mathrm{Au}$ vu de cette bonne tolérance et en fonction de la réponse, la décision de poursuite de la chimiothérapie après le $1^{\mathrm{er}}$ bilan en $2^{\text {ème }}$ ligne est prise dans plus de la moitié des cas $(54,8 \%$ des patients). Le bon état général et l'âge jeune ces patients au moment du début de la $2^{\text {ème }}$ ligne permet de dire que la chimiothérapie de $2^{\text {ème }}$ ligne est réalisable en terme de tolérance.

On note dans notre étude une différence significative en terme d'effets indésirables en fonction des différentes chimiothérapies. On retrouve une nette prévalence des effets indésirables chez les patients ayant bénéficié d'une chimiothérapie par topotécan seul par rapport au protocole paclitaxel-topotécan et CEV ou CAV. Même si ce protocole était la seule monothérapie, cela pourrait s'expliquer par la différence de posologie. Les patients ayant bénéficié de topotécan seul avait une dose de $2,3 \mathrm{mg} / \mathrm{m}^{2}$ si administré en per os, $1,5 \mathrm{mg} / \mathrm{m}^{2} \mathrm{si}$ administré en intraveineux et $1 \mathrm{mg} / \mathrm{m}^{2}$ lorsqu'il était associé au paclitaxel. Von Pawel et al. avaient dans leur étude une majorité de neutropénie de grade 4 pour le CAV et une majorité de thrombopénie de grade 4 et d'anémie de grade 3 et 4 avec le topotécan. (19) Il faut néanmoins souligner que dans notre étude les patients ayant CEV ou CAV n'était pas distingué mais un seul patient sur les 16 a eu un protocole à base d'adriamycine (CAV). Il serait intéressant de se pencher sur l'intérêt d'une réduction de dose à $1 \mathrm{mg} / \mathrm{m}^{2}$ du topotécan (en association ou non avec le paclitaxel).

L'essentiel des effets indésirables sont survenus principalement après la $1^{\text {ère }}$ cure en $2^{\text {ème }}$ ligne. Cela permet donc de palier rapidement aux différents effets indésirables en débutant le plus précocement possible les soins de support adaptés en fonction de la situation ou d'adapter les doses des chimiothérapies et ainsi d'améliorer la tolérance.

Ces progrès dans le domaine de la tolérance des cures peuvent s'expliquer par plusieurs facteurs. Dans un premier temps, on peut souligner les efforts faits dans le cadre des soins de support. Actuellement, des critères ont été définis pour l'introduction des traitements de type EPO ou ASE, traitements antiémétiques, antalgiques...qui permettent de limiter les effets secondaires classiques de la chimiothérapie. Il ne faut pas oublier l'apport croissant des aides 
paramédicales de type psychologue, assistance sociale, activités sportives, art-thérapie, esthéticienne,...

Dans un second temps, il est important de rappeler les progrès grâce à l'adaptation des protocoles de chimiothérapie en terme de dose afin de diminuer les toxicités tout en étant le plus efficace possible et d'autre part l'intensification des soins de support et mesures annexes pour améliorer au mieux la qualité de vie des patients. $(13,28)$

\subsection{Remise en question de la place de la $2^{\text {ème }}$ ligne ?}

La question de la place de la $2^{\text {ème }}$ ligne de chimiothérapie dans le CBPC n'est pas nouvelle au vu du pronostic très péjoratif de cette maladie

Nous avons montré grâce à notre étude que les 3 protocoles étaient équivalents en terme de survie sans progression et de survie globale. Ce résultat est renforcé par le fait que les 2 centres ne réalisent pas en terme d'effectif de manière équivalente les 2 protocoles. En effet, la quasi-totalité des protocoles paclitaxel-topotécan est réalisée au CH de Saint-Quentin et la quasi-totalité pour les protocoles CEV est réalisée au CHU d'Amiens. Or aucune différence significative en terme de survie sans progression n'a été mise en évidence entre les 2 centres. Von Pawel et al. ont comparé le topotécan en intraveineux au CAV chez les patients qui rechutaient à au moins 60 jours après une $1^{\text {ère }}$ ligne. Ils n'avaient pas retrouvé de différence significative en terme de médiane de survie qui étaient respectivement pour le topotécan et le $\mathrm{CAV}$ à 25 semaines et à 24,7 semaines (soit environ 6 mois) (19).

Nous avons déjà montré dans notre étude que la deuxième ligne dans cette indication était réalisable en terme d'effets secondaires. Ce qui constitue un prérequis indispensable. Il reste à savoir s'il existe un intérêt en terme de réponse.

La littérature rapporte par ailleurs une supériorité de la chimiothérapie (topotécan per os) versus les soins de support sur 141 patients qui ne pouvaient pas recevoir de chimiothérapie en intraveineux.

Il semble exister un réel intérêt à ne pas délaisser la $2^{\text {ème }}$ ligne. La survie globale de l'ensemble de notre population est supérieure à 8 mois alors que la survie sans traitement est estimée à 3 mois. Dans l'étude de O'Brien et al. même si la réponse au topotécan n'était que de 7\%. La médiane de survie pour les patients avec des soins de support seul est estimée à environ 3,5 mois versus environ 6,5 mois pour les patients avec topotécan per os (dose de 2,3 $\mathrm{mg} / \mathrm{m}^{2}$ ). Cette étude mettait également en évidence les effets indésirables liés au topotécan qui 
étaient supérieurs au groupe soins de support mais une meilleure qualité de vie. (18) Dans notre étude, la médiane de survie globale était légèrement supérieure (à 8,5 mois) mais sans sélection de la population en fonction de leur PS et sans distinction entre topotécan en intraveineux et en per os. Nous retrouvons dans notre étude des résultats similaires en terme de réponse au topotécan à $8,3 \%$.

Même si le CBPC est chimio sensible, on remarque dans notre étude que plus de la moitié $(51,6 \%)$ sont étiquetés «résistants ». La $2^{\text {ème }}$ ligne prend dès lors toute son importance car cela veut dire qu'il faudra faire face à de nombreux patients dans le futur qui seront non seulement demandeurs et en bon état général. Il est donc important de cibler la population de patients « réfractaires » afin de leur proposer rapidement une seconde ligne.

Il est important de souligner que la survie sans progression était améliorée de manière significative en fonction du statut initial au diagnostic (localisé ou disséminé). Cela signifie qu'il est important de dépister tôt cette maladie qui comme nous l'avons déjà dit, n'est que très peu symptomatique au stade localisé. Mais à l'heure actuelle, il n'existe pas de dépistage à l'échelle nationale du CBPC.

L'un des principaux facteurs pronostics dans les CBP et plus spécifiquement dans le CBPC est le tabac. Plusieurs études ont été réalisées pour évaluer si la poursuite ou le sevrage du tabagisme avait une influence sur l'efficacité du traitement. Dès 1980, Johnston-Early s'était intéressé à l'influence du sevrage tabagique sur la survie des patients atteints de CBPC traité par chimiothérapie. Il avait mis en évidence un bénéfice chez les patients sevrés avant ou au moment du diagnostic. (41) Mais les résultats des études notamment en ce qui concerne la radiothérapie restent discordants. Dans le cadre du CBPC localisé avec un traitement par RT$\mathrm{CT}$, la poursuite du tabagisme ne semble pas influencer les effets indésirables de la radiothérapie. $(42,43)$ A noter que Videtic retrouve une meilleure survie globale chez les patients sevrés mais sans qu'elle ne soit significative. On peut afin d'optimiser au maximum la prise en charge des traitements du CBPC, mettre en avant le sevrage tabagique d'autant plus qu'il permettrait l'amélioration de la qualité de vie quelque soit le stade de la maladie. (44)

\subsection{La place de la radiothérapie}

Effectivement seuls $25,8 \%$ des patients ont bénéficié d'une radiothérapie « palliative » en $2^{\text {ème }}$ ligne. Parmi ces 16 patients, 62,5\% ont été irradiés au niveau encéphalique puis au niveau osseux et médiastinal. Même si l'efficacité de la radiothérapie palliative métastatique en $2^{\text {ème }}$ 
ligne est connue, celle-ci reste un traitement contraignant (déplacements quotidiens chez des patients pouvant être altérés, douloureux...)

La présence de métastases cérébrales n'est pas retrouvée comme un facteur de mauvais pronostic quelque soit le moment d'apparition (au diagnostic, en cours de $1^{\text {ère }}$ ligne ou en $2^{\text {ème }}$ ligne). Cela est différent par rapport aux études sur le CBNPC où la présence de métastases cérébrales est un critère de mauvais pronostic. Et dans ce contexte, cette population est exclue dans les différentes études. On retrouve une franche augmentation du nombre de patients métastatiques au niveau cérébral entre la $1^{\text {ère }}$ et $2^{\text {ème }}$ ligne pour devenir en fin de $2^{\text {ème }}$ ligne le site métastatique le plus important avec $57,1 \%$ des patients. Mais il est important de rappeler que tous les patients qui avaient des métastases cérébrales au moment du diagnostic ont souvent été traités par une irradiation encéphalique et la majorité de nos patients avec un statut localisé initial ont pu bénéficier d'une IPC. Cela pourrait expliquer l'absence de modification significative de la survie sans progression en fonction de la présence de métastase cérébrale ou non.

Il a été montré que $50 \%$ de la population présentait des métastases cérébrales en $2^{\text {ème }}$ ligne. Cette augmentation par rapport à la $1^{\text {ère }}$ ligne pourrait s'expliquer de 2 manières. D'abord par la présence pour les patients localisés ou certains en réponse d'une IPC en $1^{\text {ère }}$ ligne. Puis par le fait que la bonne sensibilité à la chimiothérapie initiale.

Enfin, ce qui semblerait le plus intéressant pour le futur, c'est l'intérêt de l'irradiation stéréotaxiques. En effet, la majorité des sites métastatiques décrits sont des cibles possibles de pour cette nouvelle technique de radiothérapie. Nous avons eu, par exemple, dans notre cohorte un patient qui a une longue survie sans progression avec au moins 3 irradiations stéréotaxiques différentes (foie, cerveau et pancréas). Les études dans ce domaine sont peu nombreuses concernant le CBPC et ont porté principalement sur les localisations cérébrales. Il apparaît dans plusieurs études que la radiothérapie stéréotaxique permet un bon contrôle local pour la majorité des patients. Et celle-ci a même était testé en cas de rechute en post irradiation in toto. $(45-48)$

La question actuelle serait de savoir si, pour les patients oligo-métastatiques, il n'existerait pas un intérêt à réaliser de la radiothérapie stéréotaxique pour améliorer la survie. En effet, c'est une technique en plein essor avec peu de séances (donc courte sur la durée) et peu de comorbidités. 


\section{Conclusion}

Nous n'avons pas mis en évidence de différence significative en terme de survie sans progression et survie globale entre nos trois protocoles de chimiothérapie en deuxième ligne du CBPC. Néanmoins, nous avons pu constater que la population ayant accès à la $2^{\text {ème }}$ ligne sont des patients plutôt jeunes et en bon état général. Il existe donc un intérêt à s'intéresser à la chimiothérapie en $2^{\text {ème }}$ ligne. Dans ce cas, il est important de privilégier la tolérance. Dans notre étude, nous avons pu montrer que le protocole CEV était celui qui présentait le moins d'effets indésirables. Le topotécan seul à sa dose usuelle semble être moins bien toléré de manière générale.

La qualité de vie est un point important chez tout malade chronique. Il est donc nécessaire de l'améliorer au mieux en optimisant les soins de support, les aides paramédicales et intensifier la lutte contre le tabagisme.

Il est important de mettre l'accent sur les soins de support et plus particulièrement sur les progrès de la radiothérapie stéréotaxique qui pourraient être dans le futur, des éléments pouvant permettre de modifier la SSP en $2^{\text {ème }}$ ligne de chimiothérapie. 


\section{Bibliographie}

1. http://www.e-cancer.fr/Professionnels-de-sante/Les-chiffres-du-cancer-enFrance/Epidemiologie-des-cancers. In.

2. Locher C, Debieuvre D, Coëtmeur D, Goupil F, Molinier O, Collon T, et al. Major changes in lung cancer over the last ten years in France: the KBP-CPHG studies. Lung Cancer Amst Neth. 2013 Jul;81(1):32-8.

3. Templement $\mathrm{D}$, Westeel V. Les cancers bronchiques à petites cellules. Rev Mal Respir Actual. 2013 Sep;5(5):441-6.

4. Zelen M. Keynote address on biostatistics and data retrieval. Cancer Chemother Rep [3]. 1973 Mar;4(2):31-42.

5. Vallières E, Shepherd FA, Crowley J, Van Houtte P, Postmus PE, Carney D, et al. The IASLC Lung Cancer Staging Project: proposals regarding the relevance of TNM in the pathologic staging of small cell lung cancer in the forthcoming (seventh) edition of the TNM classification for lung cancer. J Thorac Oncol Off Publ Int Assoc Study Lung Cancer. 2009 Sep;4(9):1049-59.

6. Jett JR, Schild SE, Kesler KA, Kalemkerian GP. Treatment of small cell lung cancer: Diagnosis and management of lung cancer, 3rd ed: American College of Chest Physicians evidence-based clinical practice guidelines. Chest. 2013 May;143(5 Suppl):e400S - 19S. 7. Mascaux C, Paesmans M, Berghmans T, Branle F, Lafitte JJ, Lemaitre F, et al. A systematic review of the role of etoposide and cisplatin in the chemotherapy of small cell lung cancer with methodology assessment and meta-analysis. Lung Cancer Amst Neth. 2000 Oct;30(1):23-36.

8. Pujol JL, Carestia L, Daurès JP. Is there a case for cisplatin in the treatment of small-cell lung cancer? A meta-analysis of randomized trials of a cisplatin-containing regimen versus a regimen without this alkylating agent. Br J Cancer. 2000 Jul;83(1):815.

9. Pujol JL, Daurès JP, Rivière A, Quoix E, Westeel V, Quantin X, et al. Etoposide plus cisplatin with or without the combination of 4'-epidoxorubicin plus cyclophosphamide in treatment of extensive small-cell lung cancer: a French Federation of Cancer Institutes multicenter phase III randomized study. J Natl Cancer Inst. 2001 Feb 21;93(4):300-8. 10. Noda K, Nishiwaki Y, Kawahara M, Negoro S, Sugiura T, Yokoyama A, et al. Irinotecan plus cisplatin compared with etoposide plus cisplatin for extensive small-cell lung cancer. N Engl J Med. 2002 Jan 10;346(2):85-91.

11. Lara PN, Natale R, Crowley J, Lenz HJ, Redman MW, Carleton JE, et al. Phase III trial of irinotecan/cisplatin compared with etoposide/cisplatin in extensive-stage smallcell lung cancer: clinical and pharmacogenomic results from SWOG S0124. J Clin Oncol Off J Am Soc Clin Oncol. 2009 May 20;27(15):2530-5.

12. Rossi A, Di Maio M, Chiodini P, Rudd RM, Okamoto H, Skarlos DV, et al. Carboplatin- or cisplatin-based chemotherapy in first-line treatment of small-cell lung cancer: the COCIS meta-analysis of individual patient data. J Clin Oncol Off J Am Soc Clin Oncol. 2012 May 10;30(14):1692-8.

13. Sculier JP, Berghmans T, Castaigne C, Luce S, Sotiriou C, Vermylen P, et al. Maintenance chemotherapy for small cell lung cancer: a critical review of the literature. Lung Cancer Amst Neth. 1998 Feb;19(2):141-51.

14. Pujol JL, Breton JL, Gervais R, Tanguy M-L, Quoix E, David P, et al. Phase III double-blind, placebo-controlled study of thalidomide in extensive-disease small-cell lung cancer after response to chemotherapy: an intergroup study FNCLCC cleo04 IFCT 00-01. J Clin Oncol Off J Am Soc Clin Oncol. 2007 Sep 1;25(25):3945-51.

15. Lee SM, Woll PJ, Rudd R, Ferry D, O’Brien M, Middleton G, et al. Anti-angiogenic therapy using thalidomide combined with chemotherapy in small cell lung cancer: $\mathrm{a}$ 
randomized, double-blind, placebo-controlled trial. J Natl Cancer Inst. 2009 Aug 5;101(15):1049-57.

16.

http://www.oncologik.fr/index.php/National:Cancer_bronchique_\%C3\%A0_petit es_cellules.

17. Postmus PE, Berendsen HH, van Zandwijk N, Splinter TA, Burghouts JT, Bakker

W. Retreatment with the induction regimen in small cell lung cancer relapsing after an initial response to short term chemotherapy. Eur J Cancer Clin Oncol. 1987 Sep;23(9):1409-11.

18. O’Brien MER, Ciuleanu T-E, Tsekov H, Shparyk Y, Cuceviá B, Juhasz G, et al. Phase III trial comparing supportive care alone with supportive care with oral topotecan in patients with relapsed small-cell lung cancer. J Clin Oncol Off J Am Soc Clin Oncol. 2006 Dec 1;24(34):5441-7.

19. Von Pawel J, Schiller JH, Shepherd FA, Fields SZ, Kleisbauer JP, Chrysson NG, et al. Topotecan versus cyclophosphamide, doxorubicin, and vincristine for the treatment of recurrent small-cell lung cancer. J Clin Oncol Off J Am Soc Clin Oncol. 1999 Feb;17(2):658-67.

20. Inoue A, Sugawara S, Yamazaki K, Maemondo M, Suzuki T, Gomi K, et al. Randomized phase II trial comparing amrubicin with topotecan in patients with previously treated small-cell lung cancer: North Japan Lung Cancer Study Group Trial 0402. J Clin Oncol Off J Am Soc Clin Oncol. 2008 Nov 20;26(33):5401-6.

21. Jotte R, Conkling P, Reynolds C, Galsky MD, Klein L, Fitzgibbons JF, et al. Randomized phase II trial of single-agent amrubicin or topotecan as second-line treatment in patients with small-cell lung cancer sensitive to first-line platinum-based chemotherapy. J Clin Oncol Off J Am Soc Clin Oncol. 2011 Jan 20;29(3):287-93.

22. Von Pawel J, Jotte R, Spigel DR, O’Brien MER, Socinski MA, Mezger J, et al. Randomized phase III trial of amrubicin versus topotecan as second-line treatment for patients with small-cell lung cancer. J Clin Oncol Off J Am Soc Clin Oncol. 2014 Dec 10;32(35):4012-9.

23. Pignon JP, Arriagada R, Ihde DC, Johnson DH, Perry MC, Souhami RL, et al. A metaanalysis of thoracic radiotherapy for small-cell lung cancer. N Engl J Med. 1992 Dec 3;327(23):1618-24.

24. De Ruysscher D, Pijls-Johannesma M, Vansteenkiste J, Kester A, Rutten I, Lambin P. Systematic review and meta-analysis of randomised, controlled trials of the timing of chest radiotherapy in patients with limited-stage, small-cell lung cancer. Ann Oncol Off J Eur Soc Med Oncol ESMO. 2006 Apr;17(4):543-52.

25. Turrisi AT, Kim K, Blum R, Sause WT, Livingston RB, Komaki R, et al. Twice-daily compared with once-daily thoracic radiotherapy in limited small-cell lung cancer treated concurrently with cisplatin and etoposide. N Engl J Med. 1999 Jan 28;340(4):265-71.

26. Kies MS, Mira JG, Crowley JJ, Chen TT, Pazdur R, Grozea PN, et al. Multimodal therapy for limited small-cell lung cancer: a randomized study of induction combination chemotherapy with or without thoracic radiation in complete responders; and with wide-field versus reduced-field radiation in partial responders: a Southwest Oncology Group Study. J Clin Oncol Off J Am Soc Clin Oncol. 1987 Apr;5(4):592-600.

27. Arriagada R, Le Chevalier T, Pignon JP, Rivière A, Monnet I, Chomy P, et al. Initial chemotherapeutic doses and survival in patients with limited small-cell lung cancer. $\mathrm{N}$ Engl J Med. 1993 Dec 16;329(25):1848-52.

28. Arriagada R, Pignon JP, Le Chevalier T. Initial chemotherapeutic doses and longterm survival in limited small-cell lung cancer. N Engl J Med. 2001 Oct 25;345(17):12812. 
29. Takada M, Fukuoka M, Kawahara M, Sugiura T, Yokoyama A, Yokota S, et al. Phase III study of concurrent versus sequential thoracic radiotherapy in combination with cisplatin and etoposide for limited-stage small-cell lung cancer: results of the Japan Clinical Oncology Group Study 9104. J Clin Oncol Off J Am Soc Clin Oncol. 2002 Jul 15;20(14):3054-60.

30. Gregor A, Drings P, Burghouts J, Postmus PE, Morgan D, Sahmoud T, et al. Randomized trial of alternating versus sequential radiotherapy/chemotherapy in limited-disease patients with small-cell lung cancer: a European Organization for Research and Treatment of Cancer Lung Cancer Cooperative Group Study. J Clin Oncol Off J Am Soc Clin Oncol. 1997 Aug;15(8):2840-9.

31. Lebeau B, Urban T, Bréchot JM, Paillotin D, Vincent J, Leclerc P, et al. A randomized clinical trial comparing concurrent and alternating thoracic irradiation for patients with limited small cell lung carcinoma. "Petites Cellules" Group. Cancer. 1999 Oct 15;86(8):1480-7.

32. Jeremic B, Shibamoto Y, Nikolic N, Milicic B, Milisavljevic S, Dagovic A, et al. Role of radiation therapy in the combined-modality treatment of patients with extensive disease small-cell lung cancer: A randomized study. J Clin Oncol Off J Am Soc Clin Oncol. 1999 Jul;17(7):2092-9.

33. Le Péchoux C, Dunant A, Senan S, Wolfson A, Quoix E, Faivre-Finn C, et al. Standard-dose versus higher-dose prophylactic cranial irradiation (PCI) in patients with limited-stage small-cell lung cancer in complete remission after chemotherapy and thoracic radiotherapy (PCI 99-01, EORTC 22003-08004, RTOG 0212, and IFCT 99-01): a randomised clinical trial. Lancet Oncol. 2009 May;10(5):467-74.

34. Slotman B, Faivre-Finn C, Kramer G, Rankin E, Snee M, Hatton M, et al. Prophylactic cranial irradiation in extensive small-cell lung cancer. N Engl J Med. 2007 Aug 16;357(7):664-72.

35. Aupérin A, Arriagada R, Pignon JP, Le Péchoux C, Gregor A, Stephens RJ, et al. Prophylactic cranial irradiation for patients with small-cell lung cancer in complete remission. Prophylactic Cranial Irradiation Overview Collaborative Group. N Engl J Med. 1999 Aug 12;341(7):476-84.

36. Fox W, Scadding JG. Medical Research Council comparative trial of surgery and radiotherapy for primary treatment of small-celled or oat-celled carcinoma of bronchus. Ten-year follow-up. Lancet Lond Engl. 1973 Jul 14;2(7820):63-5.

37. Eberhardt W, Stamatis G, Stuschke M, Wilke H, Müller MR, Kolks S, et al. Prognostically orientated multimodality treatment including surgery for selected patients of small-cell lung cancer patients stages IB to IIIB: long-term results of a phase II trial. Br J Cancer. 1999 Dec;81(7):1206-12.

38. Lad T, Piantadosi S, Thomas P, Payne D, Ruckdeschel J, Giaccone G. A prospective randomized trial to determine the benefit of surgical resection of residual disease following response of small cell lung cancer to combination chemotherapy. Chest. 1994 Dec;106(6 Suppl):320S - 323S.

39. Lüchtenborg M, Riaz SP, Lim E, Page R, Baldwin DR, Jakobsen E, et al. Survival of patients with small cell lung cancer undergoing lung resection in England, 1998-2009. Thorax. 2014 Mar;69(3):269-73.

40. Bunn PA, Crowley J, Kelly K, Hazuka MB, Beasley K, Upchurch C, et al. Chemoradiotherapy with or without granulocyte-macrophage colony-stimulating factor in the treatment of limited-stage small-cell lung cancer: a prospective phase III randomized study of the Southwest Oncology Group. J Clin Oncol Off J Am Soc Clin Oncol. 1995 Jul;13(7):1632-41.

41. Johnston-Early A, Cohen MH, Minna JD, Paxton LM, Fossieck BE, Ihde DC, et al. Smoking abstinence and small cell lung cancer survival. An association. JAMA. 1980 Nov 
14;244(19):2175-9.

42. Wang J, Cao J, Yuan S, Ji W, Arenberg D, Dai J, et al. Poor baseline pulmonary function may not increase the risk of radiation-induced lung toxicity. Int J Radiat Oncol Biol Phys. 2013 Mar 1;85(3):798-804.

43. Videtic GMM, Stitt LW, Dar AR, Kocha WI, Tomiak AT, Truong PT, et al. Continued cigarette smoking by patients receiving concurrent chemoradiotherapy for limited-stage small-cell lung cancer is associated with decreased survival. J Clin Oncol Off J Am Soc Clin Oncol. 2003 Apr 15;21(8):1544-9.

44. Ruppert A-M, Amrioui F, Gounant V, Wislez M, Bouvier F, Cadranel J. [Smoking cessation therapy in thoracic oncology]. Rev Mal Respir. 2013 Oct;30(8):696-705.

45. Harris S, Chan MD, Lovato JF, Ellis TL, Tatter SB, Bourland JD, et al. Gamma knife stereotactic radiosurgery as salvage therapy after failure of whole-brain radiotherapy in patients with small-cell lung cancer. Int J Radiat Oncol Biol Phys. 2012 May 1;83(1):e539.

46. Ojerholm E, Alonso-Basanta M, Simone CB. Stereotactic radiosurgery alone for small cell lung cancer: a neurocognitive benefit? Radiat Oncol Lond Engl. 2014;9:218.

47. Olson AC, Wegner RE, Rwigema JCM, Heron DE, Burton SA, Mintz AH. Clinical outcomes of reirradiation of brain metastases from small cell lung cancer with Cyberknife stereotactic radiosurgery. J Cancer Res Ther. 2012 Sep;8(3):411-6.

48. Wegner RE, Olson AC, Kondziolka D, Niranjan A, Lundsford LD, Flickinger JC. Stereotactic radiosurgery for patients with brain metastases from small cell lung cancer. Int J Radiat Oncol Biol Phys. 2011 Nov 1;81(3):e21-7. 


\section{Annexes}

$\underline{\text { Annexe } 1: \text { Fiche de recueil de données }}$

Nom :

Prénom :

Date de naissance :

Numéro d'inclusion :

IDENTITE PATIENT

CENTRE :
0- AMIENS
1- SAINT-QUENTIN

AGE :

$$
\begin{array}{ll}
0- & <65 \text { ans } \\
1- & 65 \text { ans }<X<75 \text { ans } \\
2- & >75 \text { ans }
\end{array}
$$

SEXE :
0- FEMININ
1- MASCULIN

STATUT OMS : $0-1-2-3-4$

MOTIF DE DECOUVERTE :
0- Manifestation clinique
1- Découverte fortuite
2- Dépistage
3- Syndrome paranéoplasique
4- Autre

DATE 1ERE RCP :

TABAC :

$$
\text { 0- PAS DE TABAGISME }
$$

1 - TABAGISME ACTIF

COMORBIDITE :
0- ABSENCE DE COMORBIDITE
1- INSUFFISANCE RENALE
2- INSUFISANCE CARDIAQUE
3- INSUFFISANCE RESPIRATOIRE CHRONIQUE
4- TROUBLE NEUROLOGIQUE
5- DIABETE
6- AFFECTION DIGESTIVE
7- AUTRE

STATUT :
0- LOCALISE
1- DISSEMINE

METASTASES
0- HEPATIQUE
1- CEREBRALE
2- SURRENALE
3- OSSEUSE
4- PULMONAIRE
5- AUTRE

- $1^{\text {ère }}$ LIGNE : 
IPC REALISEE :

$0-\mathrm{NON}$

$1-$ OUI

RADIOTHERAPIE PULMONAIRE :

$$
0-\mathrm{NON}
$$

$1-$ OUI

DOSE DE CISPLATINE :

$0-\quad 80 \mathrm{mg} / \mathrm{m}^{2}$

1 - $100 \mathrm{mg} / \mathrm{m}^{2}$

2- $\quad>120 \mathrm{mg} / \mathrm{m}^{2}$

DOSE DE CARBO en AUC : 5 ou 6

NOMBRE DE CURE DE CDP - VP16

REDUCTION DE DOSE :

0- PAS DE REDUCTION

1- REDUCTION DE 25\%

2- REDUCTION DE 50\%

CHIRURGIE :

$0-\quad$ NON

$1-$ OUI

BILAN APRES L1 :

0- PROGRESSION A 3CURES

1- PROGRESSION A 6 CURES

2- STABILISATION APRES 6 CURES

3- REPONSE PARTIELLE A 6 CURES

4- REPONSE COMPLETE A 6 CURES

5- STABILISATION A 3 CURES

LOCALISATION RECHUTE :
0- HEPATIQUE
1- CEREBRALE
2- SURRENALE
3- OSSEUSE
4- PULMONAIRE
5- AUTRE

- $\quad \underline{2^{\mathrm{ème}}}$ LIGNE :

OMS : $0-1-2-3-4$

PROTOCOLE CHIMIO :

0- HYCAMTIN SEUL

1- TAXOL/HYCAMTIN

2- CEV ou CAV

DATE C1 :

DATE C2 :

DATE C3 :

EI POST CHIMIO > GRADE 2 :

$$
\begin{array}{ll}
0- & \text { NON } \\
1- & \text { OUI }
\end{array}
$$

TYPE D'EFFET INDESIRABLE :

0- ANEMIE

1- THROMBOPENIE

2- NEUTROPENIE 


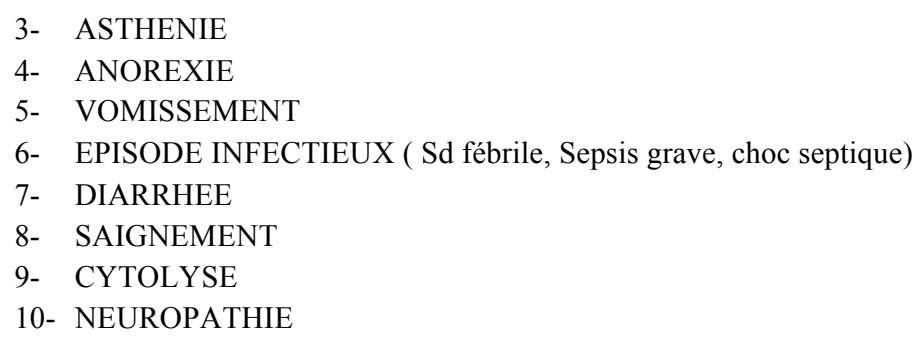

REPORT DE CURE LORS DE L2 :

$\begin{array}{ll}0- & \text { NON } \\ 1- & \text { OUI }\end{array}$

RADIOTHERAPIE PALLIATIVE :

$0-\quad \mathrm{NON}$

1- OUI

ORGANE CIBLE RADIOTHERAPIE :

0 - ENCEPHALIQUE

1- OSSEUSE

2- MEDIASTINALE

3- PULMONAIRE

4- HEPATIQUE

5- CUTANE

DOSE HYCAMTIN :

$0-1 \mathrm{mg} / \mathrm{m}^{2}$

$1-1.5 \mathrm{mg} / \mathrm{m}^{2}$

$2-\quad 2.3 \mathrm{mg} / \mathrm{m} 2$

REDUCTION DE DOSE :

0 - PAS DE REDUCTION

1- REDUCTION DE 25\%

2- REDUCTION DE 50\%

EVOLUTION :

0- REPONSE PARTIELLE-REPONSE COMPLETE

1- STABILISATION

2- PROGRESSION

TYPE D'EVOLUTION :

0 - LOCALE

1- A DISTANCE

SITE DES METASTASES APPARUES :
0 - HEPATIQUE
1- CEREBRALE
2- SURRENALE
3- OSSEUSE
4- PULMONAIRE
5- AUTRE

- APRES L2 :

OMS : 0-1-2-3-4

PROPOSITION THERAPEUTIQUE :

0- POURSUITE

1- SURVEILLANCE RADIO-CLINIQUE

2- L3

A PRECISER ... 
DATE RCP PROGRESSION :

DATE DECES :

Annexe 2 : Echelle de performance statut (PS) de l'OMS

\begin{tabular}{|c|c|}
\hline Score & Activité \\
\hline $\mathbf{0}$ & $\begin{array}{l}\text { Capable d'une activité identique à celle précédant la maladie, sans aucune } \\
\text { restriction. }\end{array}$ \\
\hline 1 & Activité physique diminuée mais ambulatoire et capable de mener un travail. \\
\hline 2 & $\begin{array}{l}\text { Ambulatoire et capable de prendre soin de soi. } \\
\text { Incapable de travailler et alité }<50 \% \text { de son temps. }\end{array}$ \\
\hline 3 & $\begin{array}{l}\text { Capable de seulement quelques soins personnels ou activités. } \\
\text { Alité ou chaise }>50 \% \text { du temps. }\end{array}$ \\
\hline 4 & $\begin{array}{l}\text { Incapable de prendre soin de lui-même. } \\
\text { Alité ou en chaise en permanence. }\end{array}$ \\
\hline
\end{tabular}

\section{Annexe 3 : Classification TNM}

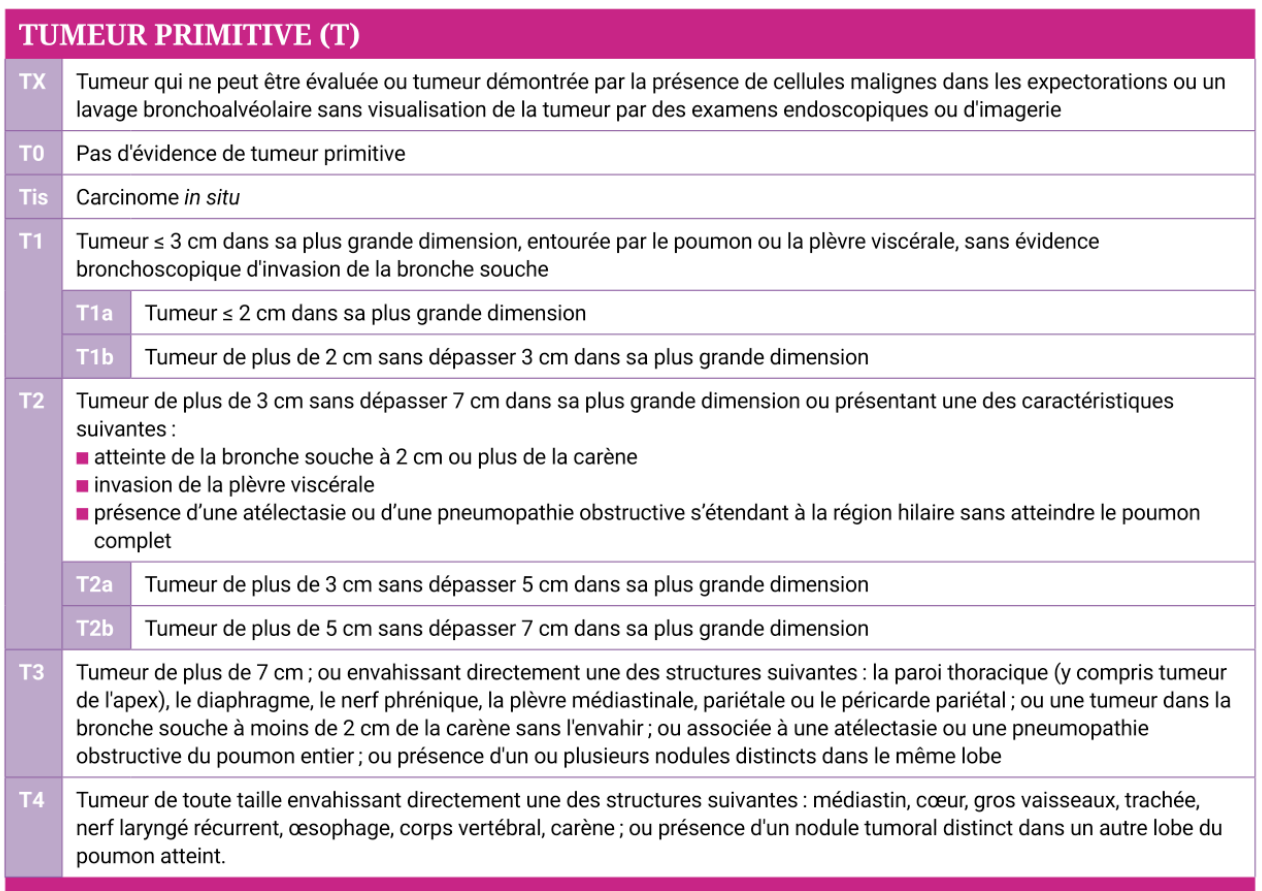

\begin{tabular}{|l|l|}
\hline \multicolumn{2}{|l|}{ ADÉNOPATHIES RÉGIONALES (N) } \\
\hline NX & Les ganglions régionaux ne peuvent être évalués \\
\hline No & Pas de métastase ganglionnaire lymphatique régionale \\
\hline N1 & $\begin{array}{l}\text { Métastase(s) dans les ganglions lymphatiques intrapulmonaires, péribronchiques et/ou hilaires homolatéraux, y compris } \\
\text { par envahissement direct }\end{array}$ \\
\hline N2 & Métastase(s) dans les ganglions lymphatiques médiastinaux homolatéraux et/ou sous carinaires \\
\hline N3 & $\begin{array}{l}\text { Métastase(s) dans les ganglions lymphatiques médiastinaux controlatéraux, hilaires controlatéraux, scalènes ou sus- } \\
\text { claviculaires homo- ou controlatéraux. }\end{array}$ \\
\hline
\end{tabular}




\begin{tabular}{|l|l|}
\hline MÉTASTASES À DISTANCE (M) \\
\hline MX & La présence de métastase(s) à distance ne peut être évaluée \\
\hline M0 & Absence de métastase à distance \\
\hline M1 & Présence de métastase(s) à distance \\
\hline \begin{tabular}{ll} 
M1a & $\begin{array}{l}\text { Nodule(s) tumoral(aux) distinct(s) dans un lobe controlatéral ; tumeur avec nodules pleuraux ou épanchement } \\
\text { pleural (ou péricardique) malin }\end{array}$ \\
\hline M1b & Métastase(s) à distance. \\
\hline
\end{tabular} \\
\hline
\end{tabular}

\begin{tabular}{|l|l|l|l|}
\hline \multicolumn{4}{|l}{ CLASSIFICATION PAR STADES } \\
\hline Carcinome in situ & Tx & N0 & M0 \\
\hline Stade 0 & Tis & N0 & M0 \\
\hline Stade IA & T1a, T1b & N0 & M0 \\
\hline Stade IB & T2a & N0 & M0 \\
\hline Stade IIA & T2b & N0 & M0 \\
\cline { 2 - 4 } & T1a, T1b & N1 & M0 \\
\cline { 2 - 4 } & T2a & N1 & M0 \\
\hline Stade IIB & T2b & N1 & M0 \\
\cline { 2 - 4 } & T3 & N0 & M0 \\
\hline Stade IIIA & T1a, T1b, T2a, T2b & N2 & M0 \\
\cline { 2 - 4 } & T3 & N1, N2 & M0 \\
\cline { 2 - 4 } & T4 & N0, N1 & M0 \\
\hline Stade IIIB & T4 & N2 & M0 \\
\cline { 2 - 4 } & Quelque soit T & N3 & M0 \\
\hline Stade IV & Quelque soit T & Quelque soit N & M1 \\
\hline
\end{tabular}


Annexe 4 : Effets toxiques aigus et subaigus des anticancéreux : cotations OMS

\begin{tabular}{|c|c|c|c|c|c|}
\hline & GRADE 0 & GRADE 1 & GRADE 2 & GRADE 3 & GRADE 4 \\
\hline \multicolumn{6}{|l|}{ HEMATOLOGIQUE } \\
\hline Hémoglobine & $>11,0 \mathrm{~g} / \mathrm{dL}$ & $9,5-10,9 \mathrm{~g} / \mathrm{dL}$ & $8,0-9,4 \mathrm{~g} / \mathrm{dL}$ & $6,5-7,9 \mathrm{~g} / \mathrm{dL}$ & $<6,5 \mathrm{~g} / \mathrm{dL}$ \\
\hline Leucocytes & $>4,0 \mathrm{G} / \mathrm{L}$ & $3,0-3,9 \mathrm{G} / \mathrm{L}$ & $2,0-2,9 \mathrm{G} / \mathrm{L}$ & $1,0-1,9 \mathrm{G} / \mathrm{L}$ & $<1 \mathrm{G} / \mathrm{L}$ \\
\hline Poly-neutrophiles & $>2,0 \mathrm{G} / \mathrm{L}$ & $1,5-1,9 \mathrm{G} / \mathrm{L}$ & $1,0-1,4 \mathrm{G} / \mathrm{L}$ & $0,5-0,9 \mathrm{G} / \mathrm{L}$ & $<0,5 \mathrm{G} / \mathrm{L}$ \\
\hline Plaquettes & $>100 \mathrm{G} / \mathrm{L}$ & $75-99 \mathrm{G} / \mathrm{L}$ & $50-74 \mathrm{G} / \mathrm{L}$ & $25-49 \mathrm{G} / \mathrm{L}$ & $<25 \mathrm{G} / \mathrm{L}$ \\
\hline Hémorragie & Absence & Pétéchies & Modérée & Moyenne & Importante \\
\hline \multicolumn{6}{|l|}{$\begin{array}{c}\text { GASTRO- } \\
\text { INTESTINAL }\end{array}$} \\
\hline Bilirubinémie & $<1,25 \times \mathrm{X}$ & $1,26-2,5 \times \mathrm{N}$ & $2,6-5 \times \mathrm{N}$ & $5,1-10 \times \mathrm{N}$ & $>10 \times \mathrm{N}$ \\
\hline Transaminases & $<1,25 \times \mathrm{X}$ & $1,26-2,5 \times \mathrm{N}$ & $2,6-5 \times \mathrm{N}$ & $5,1-10 \times \mathrm{N}$ & $5,1-10 \times \mathrm{N}$ \\
\hline Phosphatase alcaline & $<1,25 \mathrm{X} \mathrm{N}$ & $1,26-2,5 \times \mathrm{N}$ & $2,6-5 \times \mathrm{X}$ & $5,1-10 \times \mathrm{N}$ & $5,1-10 \times \mathrm{N}$ \\
\hline Muqueuse buccale & Sans changement & Douleur & Erythème & $\begin{array}{c}\text { Ulcération, } \\
\text { alimentation } \\
\text { liquide }\end{array}$ & $\begin{array}{c}\text { Alimentation } \\
\text { impossible }\end{array}$ \\
\hline $\begin{array}{c}\text { Nausées- } \\
\text { Vomissements }\end{array}$ & Absence & Nausées & $\begin{array}{l}\text { Vomissements } \\
\text { transitoires }\end{array}$ & $\begin{array}{l}\text { Vomissements } \\
\text { nécessitant un } \\
\text { traitement anti- } \\
\text { émétique }\end{array}$ & $\begin{array}{l}\text { Vomissement } \\
\text { incoercibles }\end{array}$ \\
\hline Diarrhée & Absence & $\begin{array}{l}\text { Transitoire } \\
<2 \text { jours }\end{array}$ & $\begin{array}{l}\text { Tolérable, } \\
>2 \text { jours }\end{array}$ & $\begin{array}{c}\text { Intolérable, } \\
\text { nécessité de } \\
\text { traitement }\end{array}$ & $\begin{array}{c}\text { Hémorragie } \\
\text { Déshydratatio } \\
\mathrm{n}\end{array}$ \\
\hline \multicolumn{6}{|l|}{ URINAIRE } \\
\hline $\begin{array}{c}\text { Urémie ou } \\
\text { créatininémie }\end{array}$ & $<1,25 \times \mathrm{X}$ & $1,26-2,5 \times \mathrm{N}$ & $2,6-5 \times \mathrm{N}$ & $5,1-10 \times \mathrm{N}$ & $>10 \mathrm{XN}$ \\
\hline Protéinurie & Normale & $1+$ ou $<3 \mathrm{~g} / \mathrm{L}$ & $\begin{array}{c}2 \text { ou } 3+\text { ou } 3-10 \\
g / L\end{array}$ & $4+$ ou $>10 \mathrm{~g} / \mathrm{L}$ & $\begin{array}{c}\mathrm{Sd} \\
\text { néphrotique }\end{array}$ \\
\hline Hématurie & Absence & Microscopique & Macroscopique & $\begin{array}{l}\text { Macroscopique } \\
+ \text { caillots }\end{array}$ & Anurie \\
\hline PULMONAIRE & Normal & Léger symptôme & $\begin{array}{l}\text { Dyspnée } \\
\text { d'effort }\end{array}$ & $\begin{array}{l}\text { Dyspnée } \\
\text { d'effort }\end{array}$ & $\begin{array}{l}\text { Repos au lit } \\
\text { complet }\end{array}$ \\
\hline
\end{tabular}




\begin{tabular}{|c|c|c|c|c|c|}
\hline FIEVRE/ALLERGIF & & & & & \\
\hline Fièvre & Absence & $<38^{\circ} \mathrm{C}$ & $38-40^{\circ} \mathrm{C}$ & $>40^{\circ} \mathrm{C}$ & $\begin{array}{l}\mathrm{HT}^{\circ} \mathrm{C} \text { avec } \\
\text { hypotension }\end{array}$ \\
\hline Réaction allergique & Absence & oedème & $\begin{array}{c}\text { Bronchospasm } \\
\mathrm{e}\end{array}$ & $\begin{array}{l}\text { Bronchospasm } \\
\text { e sévère sans } \\
\text { réanimation }\end{array}$ & $\begin{array}{c}\text { Choc } \\
\text { anaphylacti } \\
\text { que }\end{array}$ \\
\hline \multicolumn{6}{|l|}{$\begin{array}{l}\text { CUTANE/ALOPECI } \\
\text { E }\end{array}$} \\
\hline Cutanée & Absence & Erythème & $\begin{array}{c}\text { Desquamation } \\
\text {, vésicules, } \\
\text { prurit }\end{array}$ & $\begin{array}{c}\text { Suintement, } \\
\text { desquamation, } \\
\text { ulcération }\end{array}$ & $\begin{array}{l}\text { Fièvre avec } \\
\text { hypotension }\end{array}$ \\
\hline Effet alopéciant & Absence & $\begin{array}{l}\text { Perte de } \\
\text { cheveux }\end{array}$ & $\begin{array}{l}\text { Alopécie } \\
\text { modérée }\end{array}$ & $\begin{array}{c}\text { Alopécie } \\
\text { complète mais } \\
\text { réversible }\end{array}$ & $\begin{array}{l}\text { Alopécie } \\
\text { irréversible }\end{array}$ \\
\hline INFECTION & Absence & Mineure & modérée & Majeure & $\begin{array}{c}\text { Choc } \\
\text { infectieux }\end{array}$ \\
\hline \multicolumn{6}{|l|}{ NEUROTOXICITE } \\
\hline Etat de conscience & Vigile & assoupissement & somnolence & $\begin{array}{c}\text { Somnolence }> \\
50 \% \text { des } \\
\text { heures d'éveil }\end{array}$ & Coma \\
\hline Périphériques & Absence & $\begin{array}{c}\text { Paresthésies } \\
\text { et/ou } \\
\text { diminution des } \\
\text { réflexes } \\
\text { tendineux }\end{array}$ & $\begin{array}{l}\text { Paresthésies } \\
\text { et/ou faiblesse }\end{array}$ & $\begin{array}{c}\text { Paresthésies } \\
\text { intolérables } \\
\text { et/ou baisse } \\
\text { importante de } \\
\text { la force } \\
\text { motrice } \\
\end{array}$ & Paralysie \\
\hline $\begin{array}{l}\text { DOULEURS (non } \\
\text { liées à la maladie) }\end{array}$ & Absence & Légère & Modérée & Sévère & $\begin{array}{l}\text { Météorisme } \\
\text { et } \\
\text { vomissemen } \\
\text { ts }\end{array}$ \\
\hline
\end{tabular}

